\title{
Chronic stress increases susceptibility to food addiction by increasing the levels of DR2 and MOR in the nucleus accumbens
}

\author{
Nai-Li Wei ${ }^{1,2, *}$ \\ Zi-Fang Quan ${ }^{3,4, *}$ \\ Tong Zhao',* \\ Xu-Dong $\mathrm{Yu}^{4}$ \\ Qiang $X i{ }^{1}$ \\ Jun Zeng' \\ Fu-Kai Ma' \\ Fan Wang' \\ Qi-Sheng Tang' \\ Heng $W^{3}$ \\ Jian-Hong Zhu'
}

'Fudan University Huashan Hospital, Department of Neurosurgery, State Key Laboratory for Medical neurobiology, Institutes of Brain Science, Shanghai Medical College-Fudan University, Shanghai, 20040, People's Republic of China; ${ }^{2}$ Department of Neurosurgery, The Second Hospital of Lanzhou University, Lanzhou Gansu China, 730030, People's Republic of China; ${ }^{3}$ Department of Neurology, The First Affiliated Hospital, University of South China, Hengyang, Hunan, 42I00I, People's Republic of China; ${ }^{4}$ Institute of Neuroscience, Medical College, University of South China, Hengyang, Hunan, 42100I, People's Republic of China

*These authors contributed equally to this work

Correspondence: Heng Wu Department of Neurology, The First Affiliated Hospital, University of South China, 69 Chuanshan Rd., Hengyang, Hunan 42 I00I, People's Republic of China Email2915176817@qq.com

JianHong Zhu

Department of Neurosurgery, State Key Laboratory for Medical Neurobiology, Institutes of Brain Science, Shanghai

Medical College-Fudan University, Fudan

University Huashan Hospital, 12

Wulumuqi Zhong Rd., Shanghai 200040,

People's Republic of China

Email jzhu@fudan.edu.cn
This article was published in the following Dove Press journal:

Neuropsychiatric Disease and Treatment

Background: Stress-related obesity might be related to the suppression of the hypothalamic-pituitary- adrenocortical axis and dysregulation of the metabolic system. Chronic stress also induces the dysregulation of the reward system and increases the risk of food addiction, according to recent clinical findings. However, few studies have tested the effect of chronic stress on food addiction in animal models.

Purpose: The objective of this study was to identify whether chronic stress promotes food addiction or not and explore the possible mechanisms.

Method: We applied adaily 2 hrsflashing LED irradiation stress to mice fed chow or palatable food to mimic the effect of chronic stress on feeding. After 1 month of chronic stress exposure, we tested their binge eating behaviors, cravings for palatable food, responses for palatable food, and compulsive eating behaviors to evaluate the effect of chronic stress on food addiction-like behaviors. We detected changes in the levels of various genes and proteins in the nucleus accumbens (NAc), ventral tegmental area (VTA) and lateral hypothalamus using qPCR and immunofluorescence staining, respectively.

Results: Behaviors results indicated chronic stress obviously increased food addiction score (FAS) in the palatable food feeding mice. Moreover, the FAS had astrong relationship with the extent of the increase in body weight. Chronic stress increased the expression of corticotropin-releasing factor receptor $1(\mathrm{CRFR} 1)$ was increased in the NAc shell and core but decreased in the VTA of the mice fed with palatable food. Chronic stress also increased expression of both dopamine receptor 2 (DR2) and mu-opioid receptor (MOR) in the NAc. Conclusion: Chronic stress aggravates the FAS and contributed to the development of stress-related obesity. Chronic stress drives the dysregulation of the CRF signaling pathway in the reward system and increases the expression of DR2 and MOR in the nucleus accumbens.

Keywords: chronic stress, obesity, food addiction, dopamine receptor 2, mu-opioid receptor, nucleus accumbens

\section{Introduction}

An increasing number of studies have reported that uncontrollable stressful incidents or chronic stress states can induce obesity. Two main explanations for the observation that chronic stress induces obesity have been reported. First, chronic stress induces dysregulation of the hypothalamic-pituitary-adrenocortical (HPA) axis and increases the metabolic risk factors, such as changes in neuropeptide Y (NPY), insulin, and cortisol levels, among others. ${ }^{1-3}$ Peripheral hormone changes induce an abnormal body fat distribution and body weight gain. ${ }^{4,5}$ Second, chronic stress induces dysregulation of 
the reward system and increases cravings for palatable food. ${ }^{6,7}$ Palatable food comforts individuals in the stressed state and increases food consumption in response to stress. ${ }^{8,9}$ However, neither of those hypotheses adequately explain compulsive eating behaviors in individuals subjected to chronic stress. During acute severe stress, an increased corticotropin-releasing factor (CRF) level may reverse animals' appetitive response to palatable food to an aversive response, whereas people who experience severe stress exhibit an increased vulnerability to obsessive-compulsive disorders. ${ }^{10,11}$ Compulsive eating behavior is the main characteristic of food addiction. Moreover, chronic stress has recently been shown to result from the development of a food addiction. Posttraumatic stress disorder symptoms are associated with an increased risk of becoming overweight or obese. ${ }^{12}$ Furthermore, symptoms of posttraumatic stress disorder are associated with an increased prevalence of food addiction in a cohort of women. ${ }^{13}$ Thus, food addiction may be another important factor contributing to stress-induced obesity.

Over the past decade, the concept of food addiction has attracted increasing attention because it has been shown to have a strong relationship with obesity. ${ }^{14-17}$ More than half of the severely obese population meets the diagnostic criteria for food addiction. ${ }^{17}$ A higher food addiction score (FAS) results in a greater body weight gain. In addition, the FAS has been used as a predictive factor for weight loss. ${ }^{18}$ These convincing data suggest that food addiction may be a major cause of obesity.

Thus, we postulate that chronic stress increases the vulnerability to food addiction and subsequently contributes to stress-induced obesity. In the present study, we verified our hypothesis and explored the possible mechanisms.

\section{Methods}

\section{Subjects}

Male C57/BJ mice, 4-week old on arrival (SLAC Laboratory, Changsha, China), were raised in plastic cages in a 12-h reverse light cycle with free access to lowfat food (standard chow containing 10\% fat by calories and $3.28 \mathrm{kcal} / \mathrm{g}$; Academy of Military Medical Sciences, Beijing, China) and water.

The study was approved by Institutional Animal Care and Use Committee of both University of the South China and Fudan University. All procedures were carried out in accordance with Guidance for Animal Experimentation of the University of the South China, Guidance for Animal
Experimentation of Fudan University and the Chinese Guidelines for Care and Use of Laboratory Animals.

\section{Test the effect of acute light stress on feeding behaviors}

Twenty-four mice were divided into three groups: a control group, a white LED light group and a flashing LED light group. At 6:00 pm and 12:00 pm, mice were provided with chow or palatable food. We measured their food intake for 3 hrs. In the first hour, mice in all groups were fed in the dark and their baseline volume of food intake was measured. In the second and third hours, mice in the control group were fed in the dark, mice in the white LED group were fed in the presence of a white LED light, and mice in the flashing LED light group were fed in the presence of a flashing LED light. Food intake was measured hourly.

\section{Test the effect of ultrasound waves on feeding behaviors and locomotion}

The ultrasonic rat repellent sends out ultrasound at three different frequencies: an electromagnetic wave of $0.8-8 \mathrm{~Hz}$ for an interval of $160 \mathrm{~s}$, an ultrasound wave of $20-50 \mathrm{kHz}$ for an interval of $80 \mathrm{~s}$ and an ultrasound wave of $35 \mathrm{kHz}$ for an interval of $80 \mathrm{~s}$. The device imitates the vocalizations of threatened young mice that disturb adult mice and thus arouses fear and escape behaviors. ${ }^{19}$ It provides an aversive feeding environment and disturbs the appetite. Before the experiment, we conducted preliminary studies to test whether the ultrasonic rat repellent induced negative effects. Twentyfour mice were divided into two groups: an ultrasound group and a control group. Mice in both groups were fed chow or palatable food in the dark. In the second half hour, mice in the ultrasound group were exposed to the ultrasonic rat repellent. Food intake was measured every half hour.

We also performed open-field tests to test the effect of the ultrasonic rat repellent on spontaneous activities. Animals were placed in the open field apparatus (Med Associates, USA) for 30 mins to allow them to acclimate to the environment. Then, the mice were placed in the open-field system and the system recorded activity in 10 mins intervals. Their total distance traveled and time spent in the central area were recorded to evaluate the effect of the ultrasonic rat repellent.

\section{Effect of chronic stress induced by flashing LED irradiation on food addiction}

After 2 weeks of acclimation, 40 mice were subjected to the chronic stress experiment. Animals were randomly divided 
into four groups: chow group, fat-bingeing group, chronic stress/chow group and chronic stress/fat-bingeing group. The daily food intake of the mice in each group was measured as the baseline level of energy consumption for the following week. In order to induce food addiction-like behaviors, we applied a fat-bingeing protocol, which was previously reported. ${ }^{20,21}$ From 6 pm to $8 \mathrm{pm}$, mice in the fat-bingeing group and chronic stress/fat-bingeing group were supplied with palatable food (containing $45 \%$ fat by calories and 4.58 $\mathrm{kcal} / \mathrm{g}$; Academy of Military Medical Sciences), and mice in the other groups were supplied with low-fat food. In order to induce chronic stress effect, we applied a daily flashing LED light irradiation which was proved to take a negative effect on feeding behaviors. Mice in the chronic stress/chow group and chronic stress/fat-bingeing group were exposed to the flashing LED light source (consisting of an LED array of 3 LEDs, 240-300 $\mathrm{lm} \cdot \mathrm{s} \cdot \mathrm{m}^{-2}$, colorful flashes converted randomly among seven colors, 1 array/1 cage, Figure 1). Mice in other groups were fed in the dark.

Throughout the duration of food addiction induction, 2 hrs food intake from 6:00 pm to 8:00 pm, $22 \mathrm{hrs}$ food intake from 8:00 pm to $6: 00 \mathrm{pm}$, body weight were measured.

\section{Protocol for the food addiction behavioral tests}

After 1-month period of flashing LED-induced chronic stress, mice in all groups were deprived of food for $24 \mathrm{hrs}$ to test the food-withdrawal dependence behavior. First, anxiety-like behaviors were tested using the light/dark conflict test and elevated plus maze test. Then, the palatable food craving test was conducted with mice in all groups by supplying the animals with palatable food. The 2 hrs palatable food intake was measured to determine their cravings for palatable food. After these tests, all mice had 1 day of rest with access to low-fat food and water. Then, the motivation for food was evaluated in the dark-light conflict system. Next, another 24 hrs fast was conducted and compulsive eating behaviors were evaluated (Figure 1). After these experiments, the mice were sacrificed, and their brains were removed for qPCR and immunofluorescence staining.

\section{Anxiety-like behaviors \\ Elevated plus maze test}

The elevated plus-maze test was performed as previously described. ${ }^{22}$ The following parameters were used to evaluate anxiety-related behavior: the percentage of total arm time in the open arms (ie, $100 *$ open arm time/(open arm time + closed arm time)) and the number of entries into the open arm.

\section{Light/dark conflict test}

The test was performed as previously described. ${ }^{20}$ The following parameters were used to evaluate anxietyrelated behavior: the percentage of total time in the light box (ie, $100 *$ light box time/(light box + dark box time)) and the number of entries into the light box.

\section{Binge-like eating test}

Binge-like eating behaviors in mice are defined as the consumption of one-third of their normal total daily caloric intake within $2.5 \mathrm{hrs}$ of palatable food presentation. ${ }^{21} \mathrm{We}$ measured the palatable food consumption from $6: 00 \mathrm{pm}$ to 8:00 pm over 5 days to evaluate the binge-like eating behaviors of mice in the chronic stress/fat-bingeing group and fatbingeing group. The mean palatable food consumption was compared with the control group to evaluate the behavior.

\section{Motivation for palatable food}

We measured the animals' cravings for palatable food after fasting and responding to food signals to evaluate their motivation for palatable food.

\section{Craving for palatable food after fasting}

After the tests of anxiety-related behaviors, mice in each group were provided palatable food. The energy consumption in $2 \mathrm{hrs}$ was recorded to evaluate cravings for palatable food.

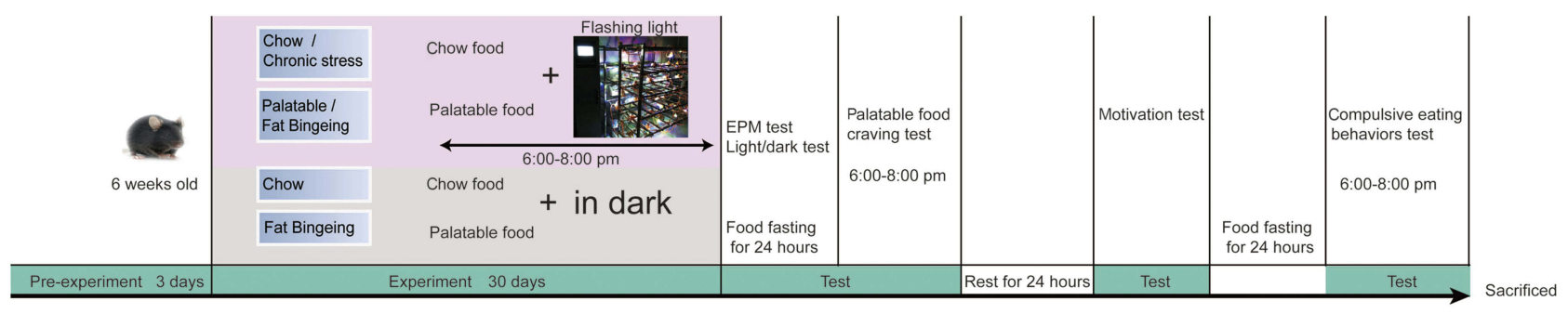

Figure I Schematic of the experiment.

Abbreviation: EPM, Elevated plus maze test. 


\section{Food signal response test}

After $24 \mathrm{hrs}$ of rest, mice were placed in the light/dark box for 20 mins and their responses to palatable food were measured in the dark/light conflict system. Food was placed in a container and suspended from the ceiling of the light box. The mice could smell the odor of the food but not touch it. First, low-fat food was used in the test. When the food was placed in the apparatus, the mice were allowed to acclimate to the test environment for the first 5 mins. Videos of the activity of the mice were recorded for the next 5 mins. The recorded activity trajectories were analyzed with the Wablab system. Then, the mice were removed from the apparatus, and their odor cues were removed. The palatable food seeking motivation test was performed in the next 10 mins, and the same procedure was used as described above for the lowfat food. The percentage of total time animals spent in the light box when palatable food was present (ie, $100 *$ light box time/(light box + dark box time) $)$ and the difference in the percentage of total time spent in the light box between palatable food and low-fat food signals were used to evaluate the responses to food signals. Both the palatable food craving and the time spent in the light box were used to evaluate the motivation for palatable food.

\section{Compulsive eating}

Compulsive behaviors are described as compulsive use despite negative consequences. ${ }^{23}$ We placed the mice in the feeding field and exposed them to ultrasonic rat repellent to model compulsive eating behaviors. The ultrasonic rat repellent sends out ultrasounds with three different frequencies: an electromagnetic wave of $0.8-8 \mathrm{~Hz}$ for an interval of $160 \mathrm{~s}$, an ultrasound wave of $20-50 \mathrm{kHz}$ for an interval of $80 \mathrm{~s}$ and an ultrasound wave of $35 \mathrm{kHz}$ for an interval of $80 \mathrm{~s}$. The device imitates the vocalizations of threatened young mice that disturb adult mice and thus arouses fear and escape behavior. ${ }^{19}$ It provides an aversive feeding environment and disturbs the appetite. After the motivation test, all mice (1 mouse/ 1 cage) were placed in an open field $\left(16 \mathrm{~m}^{2}\right)$ without obstacles. The ultrasonic rat repellent was suspended $1 \mathrm{~m}$ above the cages, ensuring that each mouse was exposed to the ultrasonic wave equally. The animals had access to palatable food for $2 \mathrm{hrs}$. The energy consumption in $2 \mathrm{hrs}$ was recorded to evaluate the compulsive eating behavior.

\section{Food addiction score}

Previous papers reported excessive intake, heightened motivation for food and compulsive-like eating as the main parameters to evaluate food addiction-like behaviors in animal models. ${ }^{21,24}$ We compared the value recorded for each mouse with mean value for the mice in the control group (chow group) to evaluate these parameters. When the value of the parameter exceeded the mean $\pm 2 \mathrm{SD}$ of the control group, this value was defined as a positive result. For example, energy consumption in the binge-like eating behavior test received a score of 1 point when the value exceeded the mean \pm 2 SD of the chow group. Energy consumption recorded in the compulsive eating behavior test received a score of 1 point when the value exceeded the mean $\pm 2 \mathrm{SD}$. The FAS for each mouse was calculated as the algebraic sum of individual scores for each of these food addiction-like behaviors.

\section{Brain tissue microdissection and $\mathrm{qPCR}$}

After all tests, the mice were sacrificed. Their brains were quickly removed, frozen and stored at $-80^{\circ} \mathrm{C}$ prior to the PCR analysis. Samples of the nucleus accumbens shell subregion (NAc-sh), nucleus accumbens core subregion (NAc-Co), lateral hypothalamus (LH) and ventral tegmental area (VTA) were microdissected on a freezing microtome. Briefly, the brain was frozen, placed in a tissueprocessing cassette and surrounded with embedding medium. We held the brain with forceps to ensure the proper horizontal orientation of the brain. The frozen and embedded brain was sliced using the freezing microtome in the rostral to caudal direction (Figure 2). We used a $0.25-\mathrm{mm}^{2}$ punch to microdissect the shell and core of the NAc from the brain tissue, as shown in Figure 1B. The lateral ventricle was used to judge the boundaries of the core and shell subregions of the NAc. LH and VTA tissues were dissected using the same methods.

\section{Immunofluorescence staining and cell counting}

Frozen sections from mice in each group were subjected to immunofluorescence staining to further examine the stressinduced molecular changes in the NAc. Briefly, rats were euthanized at 12 weeks by an overdose of anesthesia. The brains were dissected and postfixed with $4 \%$ formaldehyde for 2 days. After dehydration in a sucrose solution, the brains were embedded with Leica OCT and then sectioned at $12-\mu \mathrm{m}$ thickness. After blocking with serum, sections were incubated with primary anti-mu-opioid receptor (MOR) (ab10275, Abcam, USA) and dopamine (DA) receptor 2 (DR2) antibodies (ARG10779, arigo, China). Then, the sections were incubated with donkey anti-rabbit 

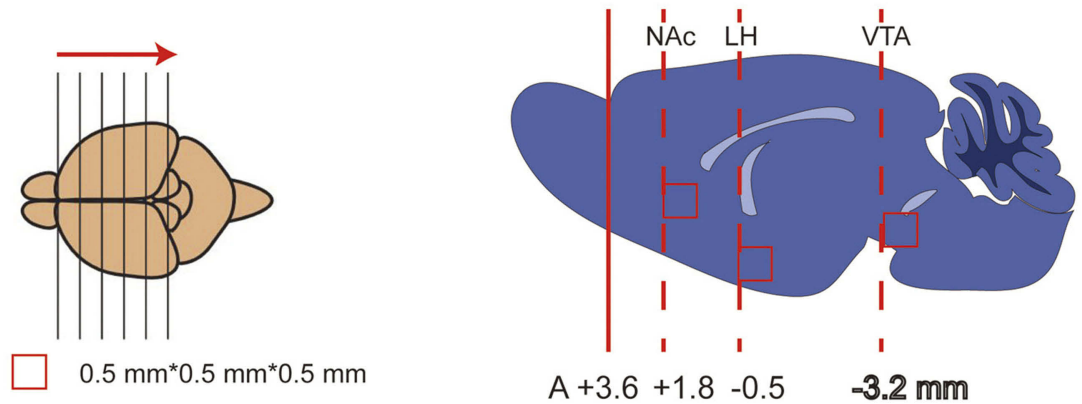

A

NAc

LH

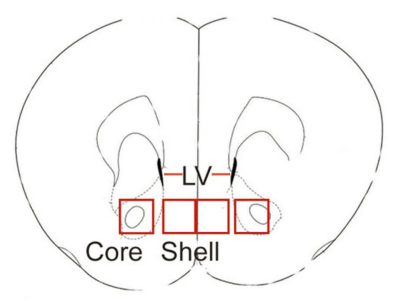

B

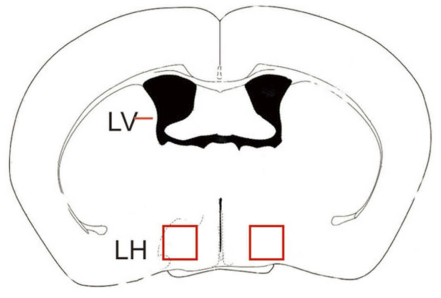

C
VTA

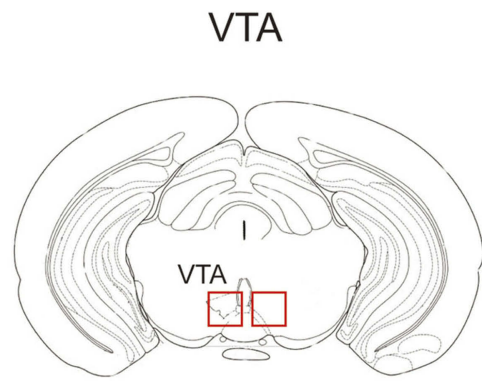

D

Figure 2 Schematic of the brain tissue microdissection for QPCR tests. (A) The frozen and embedded brain was sliced into sections from the rostral to caudal direction using a freezing microtome. When the slice was at the level of the target nucleus, a $0.5^{*} 0.5^{*} 0.5 \mathrm{~mm}^{3}$ tissue was dissected from the corresponding nucleus. The locations of the nucleus accumbens, LH and VTA are displayed in the right panels of Figure 2A. (B - D) Locations of the nucleus accumbens shell and core (Figure 2B), LH (Figure 2C), and VTA (Figure 2D) in the coronal plane. LH, lateral hypothalamus; LV, lateral ventricle; NAc, nucleus accumbens; Shell, nucleus accumbens shell; Core, nucleus accumbens core; VTA, ventral tegmental area.

IgG antibodies to detect DR2 and MOR (ab150075, Abcam), followed by staining of the nuclei with hematoxylin. Images were captured and analyzed using a confocal microscope (DMRE; SP5 microscope, Leica, Wetzlar, Germany). Regions of interest were defined bilaterally in the NAc core and NAc shell $(1.0-1.7 \mathrm{~mm}$ anterior to the bregma). The MOR-positive or DR2-positive cells were quantified using the Image-Pro Plus software package (Media Cybernetics).

\section{Statistics}

The results are presented as mean \pm SEM. During the period of addiction-like behavior induction, food intake data are reported as the daily energy consumption on the odd days of the consecutive 30 days. One-way ANOVA tests were used to detect differences in 2 hrs consumption and $24 \mathrm{hrs}$ consumption of each group in the consecutive 30 days to assess the changes in energy consumption over time. Two-way ANOVA with Bonferroni's post hoc tests were used to detect the differences in the trends of energy consumption between two groups. Parametric data, including the FAS, the body weight increase, qPCR results and the percentage of positive cells were analyzed using
Student's independent sample $t$-test and the Wilcoxon signed-rank test. Both logistic regression and linear regression methods were used to analyze the relationship between the FAS and body weight increase. GraphPad Prism v 6.0 (GraphPad Software, San Diego, CA, USA) was used for the statistical analyses.

\section{Results}

\section{Stress promotes the daily consumption of palatable food}

Stress induced by an acute white LED light with an intensity of $300 \mathrm{~lm} \cdot \mathrm{s} \cdot \mathrm{m}^{-2}$ decreased palatable food consumption, but the animals became habituated to this stress (Figure 3D). However, the effect was longer lasting when mice were exposed to a flashing LED light. Thus, we applied the flashing LED light with an intensity of $300 \mathrm{~lm} \cdot \mathrm{s} \cdot \mathrm{m}^{-2}$ as the chronic stressor in the chronic stress experiment. We measured the daily 2 hrs food consumption from $6: 00 \mathrm{pm}$ to $8: 00 \mathrm{pm}$ and $24 \mathrm{hrs}$ food consumption over 30 consecutive days. In the first 5 days, Flashing LED stress decreased food consumption both in mice fed chow and palatable food (Figures 4 and 5). On the following days, the animals 
A

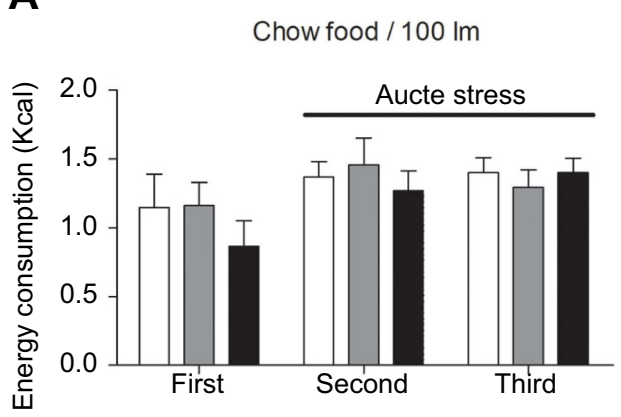

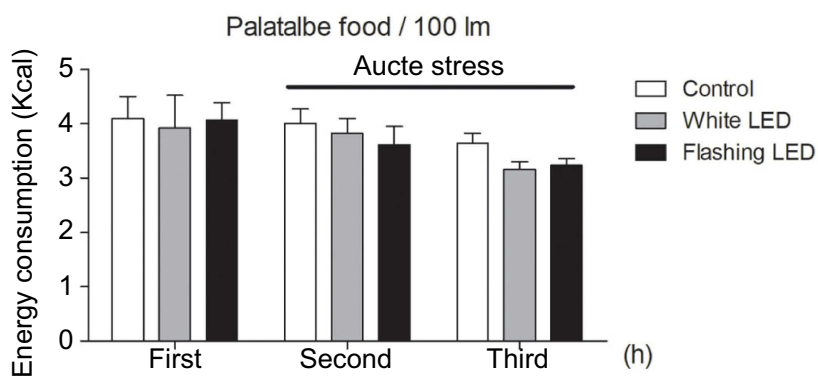

C

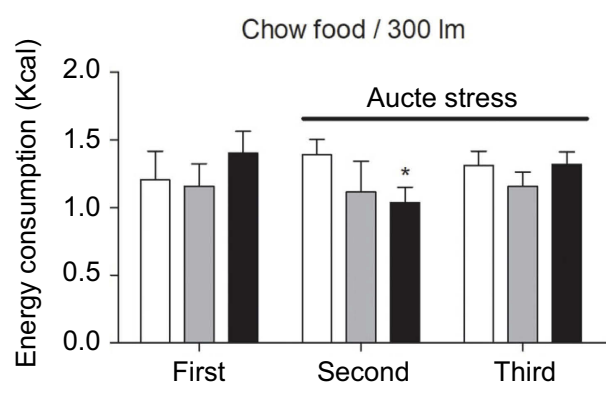

$\square$ Control

$\square$ White LED

Flashing LED
B

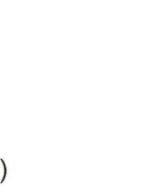

D

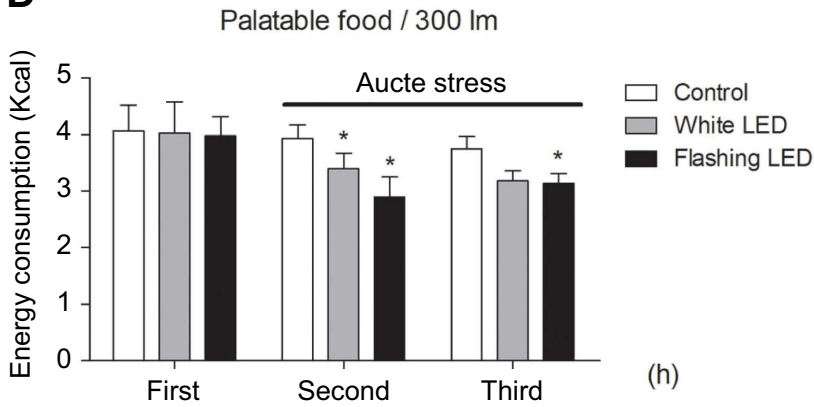

Figure 3 Stress induced by an acute flashing LED light decreased the consumption of both chow and palatable food. (A) Effect of LED (with lihgt intensity of I00 Im/s) stress on chow food intake; (B) Effect of LED (with lingt intensity of $100 \mathrm{~lm} / \mathrm{s}$ ) stress on palatable food intake; (C) Effect of LED (with lihgt intensity of $300 \mathrm{Im} /$ s) stress on chow food intake; (D) Effect of LED (with lingt intensity of $300 \mathrm{~lm} / \mathrm{s}$ ) stress on palatable food intake. * denotes significant differences compared with the control group $(* P<0.05)$.

Abbreviation: LED, Light Emitting Diode.

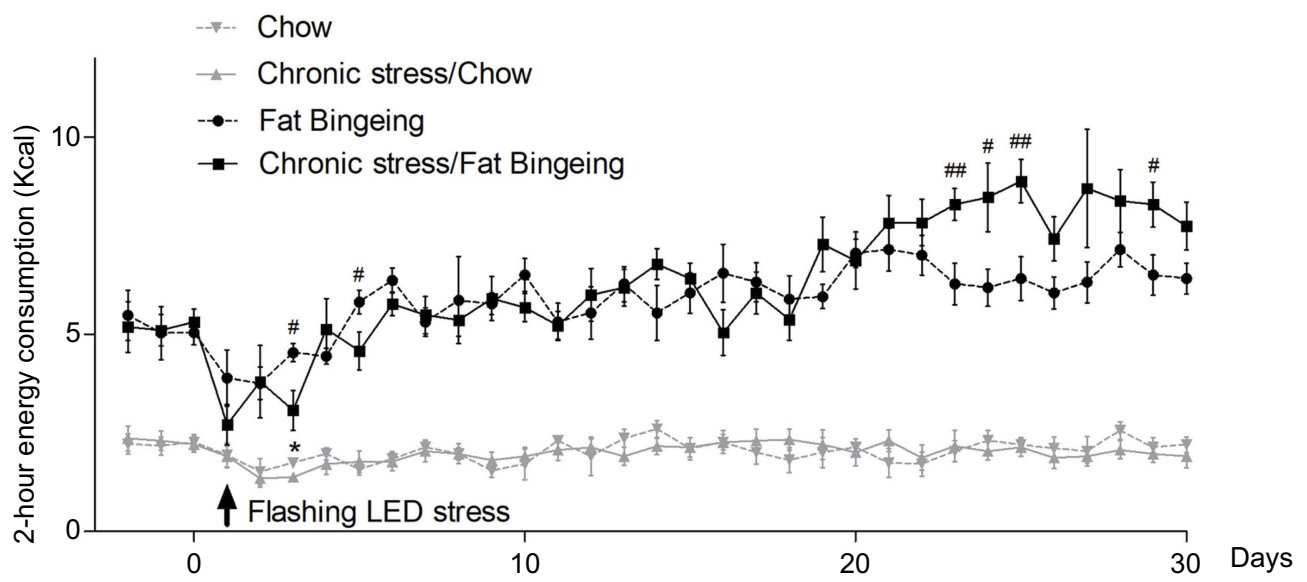

Figure 4 Effect of chronic stress on daily food intake measured from 6:00 pm-8:00 pm in each group. $*$ denotes significant differences in daily food intake between the chronic stress/chow group and chow group, and \# denotes significant differences between the fat-bingeing group and chronic stress/fat-bingeing group $\left(* P<0.05\right.$, ${ }^{*} P<0.05$, and $\left.{ }^{\#} P<0.01\right)$.

became habituated to the stressor. However, the effect of the stressor on the chronic stress/fat-bingeing group did not disappear. Mice in the chronic stress/fat-bingeing group consumed more palatable food after 20 days. Mice in the fat-bingeing group and chronic stress/fatbingeing group tended to consume more palatable food in the 2 hrs palatable food consumption test, but the mice in the chow group and chronic stress/chow group did not change their food consumption (Figures 4 and 5). However, only the mice in chronic stress/fatbingeing group exhibited an increasing trend in 24 hrs food consumption. 


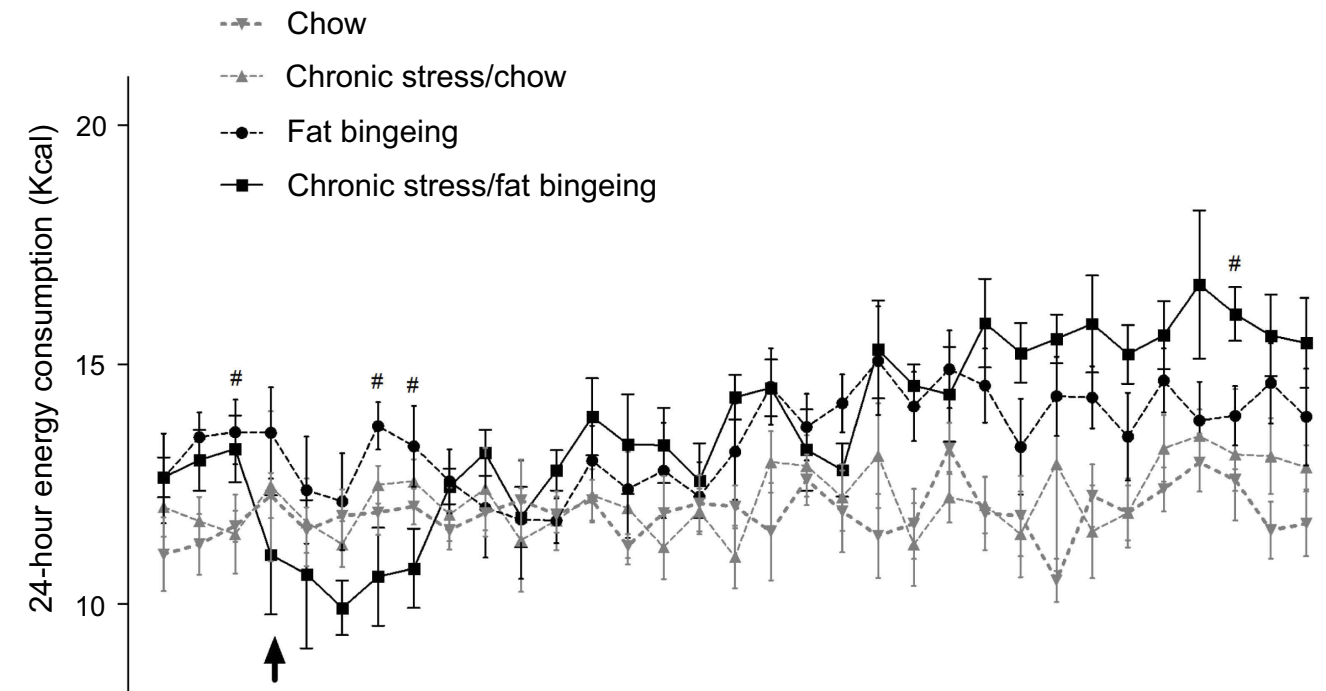

Flashing LED stress

0

10

20

30

Days

Figure 5 Effect of chronic stress on daily 24 hrs food intake. \# denotes significant differences between the fat bingeing and chronic stress/fat bingeing $\left({ }^{\#} P<0.05\right)$.

A

Elevated plus-maze test

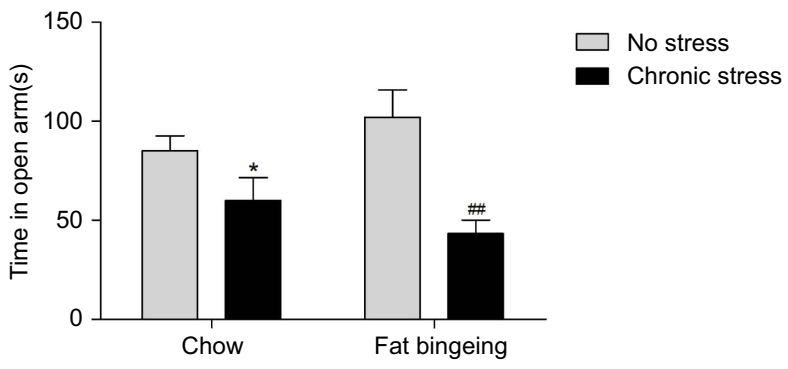

C
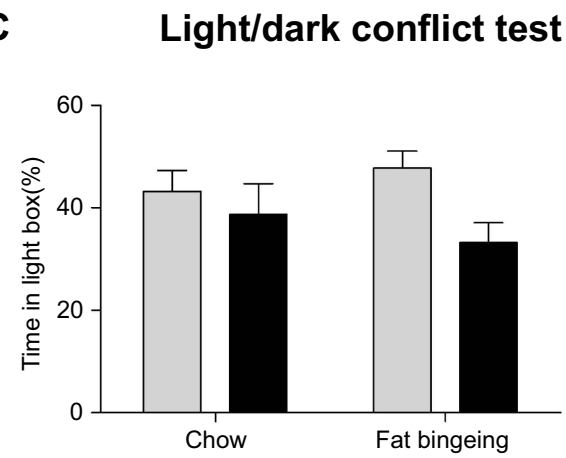

B Elevated plus-maze test

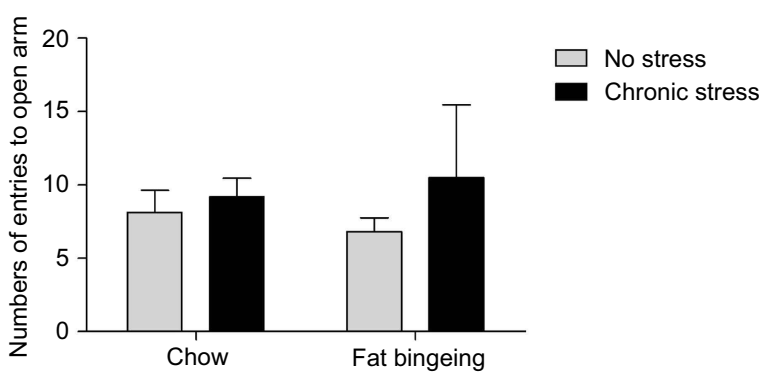

D Light/dark conflict test

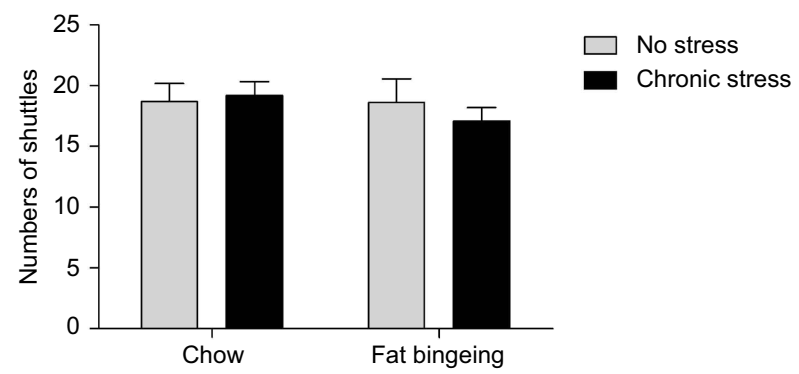

Figure 6 Chronic stress aggravates anxiety-like behaviors. (A) Chronic stress decreased the time in open arm of the mice both in the chow and fat-bingeing feeding mice in the test of EPM test. But chronic stress took no significant effect on the numbers of entries to the open arm (B), time in the light box (C) and shuttle times (D) in the Light/ dark conflict test. * denotes significant differences between chow group and chronic stress/chow group $(* P<0.05)$. ${ }^{\#}$ denotes significant differences between fat bingeing and chronic stress/fat bingeing group. $\left({ }^{\#} P<0.001\right)$. 


\section{Flashing LED stress aggravates anxiety-like behaviors}

We conducted an anxiety behavior test to measure the effect of the chronic stressor. The flashing LED stressor exerted a long-lasting effect on the anxiety behaviors (Figure 6). Although significant differences in the light/ dark conflict test were not observed between groups, the mice in chronic stress groups showed anxiety-like behaviors in the elevated plus maze test.

\section{Palatable food induces binge-like eating behaviors, but chronic stress enhances the outcome}

After interment palatable food feeding from 6:00 pm to 8:00 $\mathrm{pm}, 1$ of 10 mice in the fat-bingeing group exhibited binge-like behaviors, while 2 of 10 mice in the chronic stress/fat-bingeing group exhibited these behaviors. No mice in other groups exhibited binge-like eating behaviors. However, mice in the chronic stress/fat-bingeing group consumed excess amounts of palatable food compared with the other groups (Figure 7).

\section{Motivation for palatable food increases in the fat-bingeing models, but chronic stress enhances the outcome}

In the present study, we measured food signal response and the palatable food cravings to evaluate the motivation for palatable food. We used two types of food signals in the food signal response test: palatable food and chow food. Food signal can attack mice to seek for food (Figure 8A). Mice spent different amounts of time in the light box in the presence of different food signals. When animals were exposed to chow signal, no significant differences in the time spent in the light box and the number of shuttles from the light and dark boxes were observed between the different groups. However, when the mice were exposed to the palatable food signal, the mice in the fat-bingeing group and chronic stress/fat-bingeing group spent more time in light box where the palatable food was located (Figure 8B-C). The data indicated that mice with fat-bingeing always increased responding for palatable food than control group. After a $24 \mathrm{hrs}$ fast, the mice in all groups were provided palatable food to measure their cravings for palatable food. Mice in the chronic stress/fat-bingeing group consumed more palatable food than the control group (Figure 8D). The data indicated that chronic stress and repeated palatable food feeding coenhanced palatable food craving. The time spent in the light box in the presence of palatable food signal, but not the chow signal, exhibited a strong relationship with the craving for palatable food (Figure 8E and F).

\section{Chronic stress aggravates compulsive eating behaviors in mice fed palatable food}

The ultrasonic rat repellent used in the present study sends out ultrasound waves with frequencies of 20-50 $\mathrm{kHz}$ and exerts negative effects on both food intake and locomotion. The ultrasound wave decreased the intake of both chow and palatable food (Figure 9A and B). Moreover, the mice exposed to the ultrasound wave exhibited anxiety behaviors, as evidenced by less time spent in the central of the open field, although the distance traveled increased (Figure 9C and D). Thus, our present study applied this method to evaluate compulsive eating behaviors. In the compulsive eating behavior test, chronic stress aggravated compulsive eating behavior in fat bingeing mice (Figure 9E). In addition, food consumption in the presence of the ultrasound
A

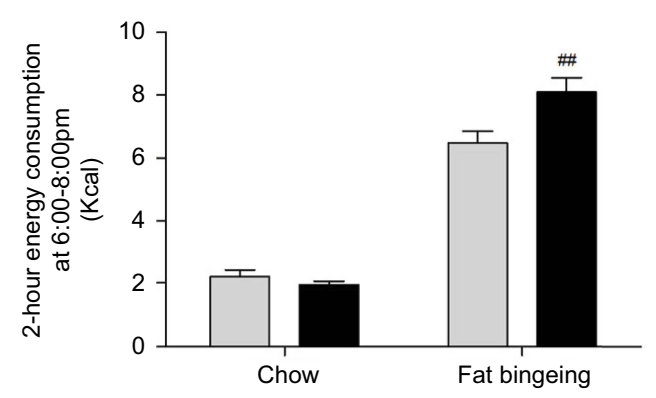

B

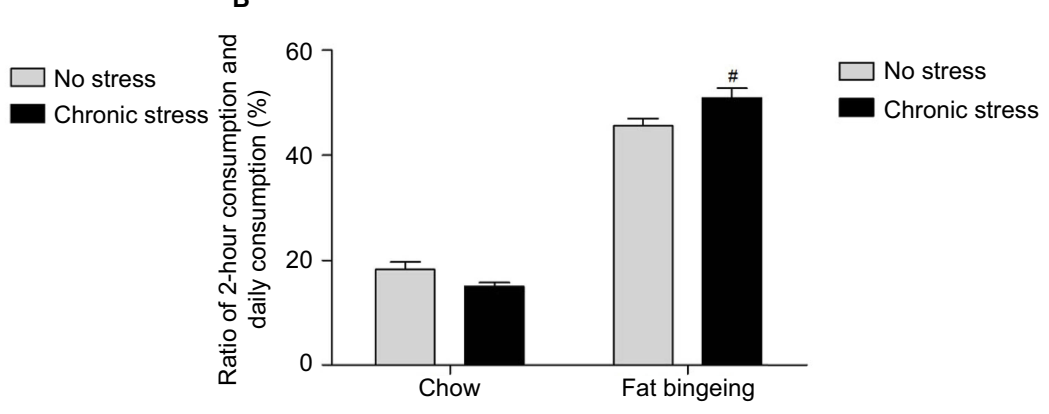

Figure 7 Chronic stress promotes binge eating behaviors in mice fed palatable food. (A) Chronic stress increase daily $2 \mathrm{hr}$ energy consumption of palatable food in fat bingeing mice; (B) The ratio of food consumption at $6: 00 \mathrm{pm}$ to $8: 00 \mathrm{pm}$ of daily food consumption increased in the fat bingeing mice in chronic stress. denotes significant differences between the fat-bingeing group and chronic stress/fat-bingeing group $\left({ }^{\#} P<0.05\right.$ and $\left.{ }^{\#} P<0.01\right)$. 


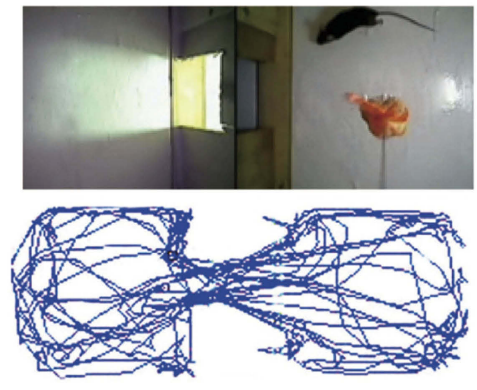

A

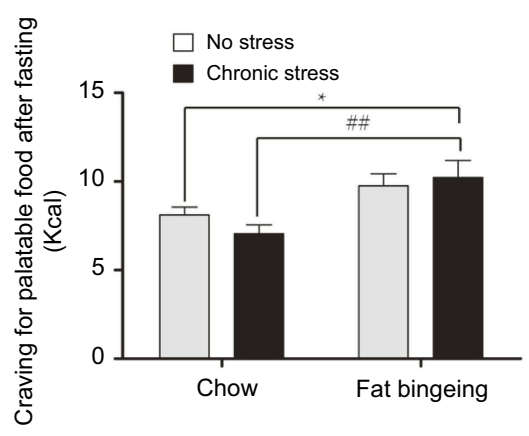

D

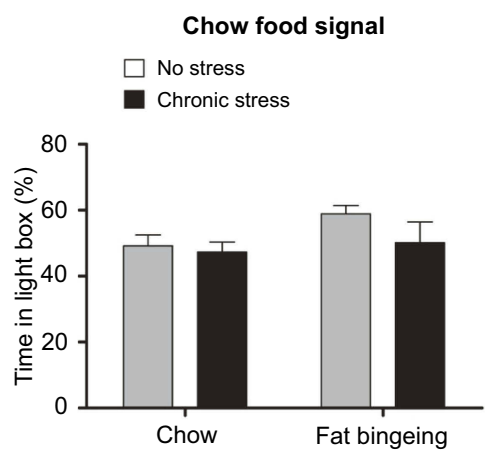

B

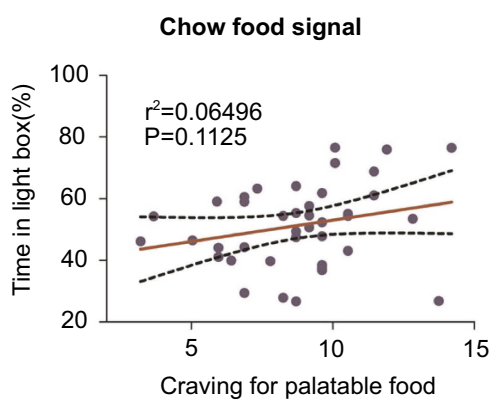

E

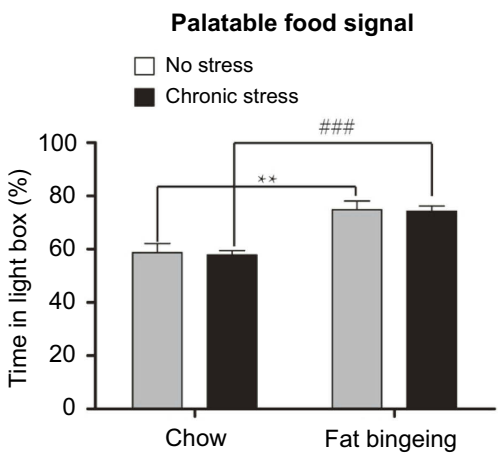

C

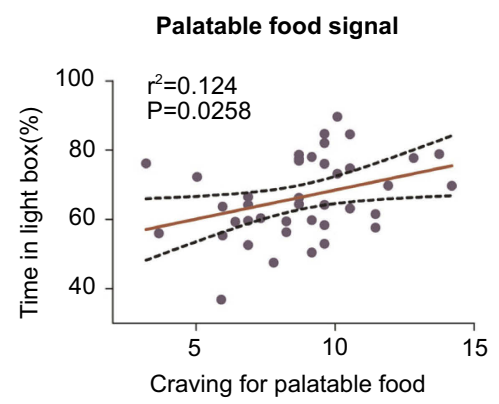

F

Figure 8 Fat-bingeing increases the motivation for palatable food, but chronic stress enhances the outcomes. In our motivation test, we suspended the food above the floor of the light box. The activity trajectories of the mice were analyzed by reprocessing the video recordings (A). Upon exposure to the chow food signal, there were no significant differences among groups (B). Upon exposure to the chow food signal, mice in fat-bingeing group and chronic stress/fat-bingeing group spent more time in the light box $(\mathbf{C})$. Fat-bingeing increases craving for palatable food after fasting (D). Time in the light box in the presence of the palatable food (E) but not chow food (F) was positively correlated with the craving for palatable food. * denotes significant differences between chow group and due group; \# denotes significant differences between chronic stress group and due group $\left({ }^{*} P<0.05 ;{ }^{* * P} P 0.01 ;{ }^{\#} P<0.0 I^{\# \#} P<0.001\right)$.

wave might predict the severity of food addiction. We analyzed the relationship between the FAS and palatable food consumption in the presence of the ultrasound wave. The results revealed a positive correlation between the FAS and compulsive eating. Mice with a higher FAS consumed more palatable food in the compulsive behavior test.

\section{Food addiction score and body weight increase}

In the present study, acute stress decreased the body weight of mice in chronic stress/chow group and chronic stress/fatbingeing group during the first few days. Over the following days, mice appeared to habituate to the stressor. However, the body weight of mice fed palatable food while exposed to chronic stress appeared to increase faster than mice in the other groups (Figure 10A). Chronic stress promoted the progression of obesity in the fat-bingeing groups.

We compared the test results for each mouse with the reference range defined as the mean value $\pm 2 \mathrm{SD}$ of the control group (chow group) to evaluate food addiction. Chronic stress aggravated FAS in fat bingeing mice (Figure 10A). Additionally, the FAS was positively correlated with the increase in body weight (Figure 10C). The mice with high FASs exhibited a greater increase in body weight.

\section{CRFRI, DR2 and MOR mediated the effect of chronic stress on food addiction-like behaviors}

We assessed the expression of the CRF1 mRNA in the NAc core and shell, LH and VTA to investigate the molecular changes induced by chronic stress. Chronic stressinduced dysregulation of the CRF system. The expression of the CRF receptor 1 (CRFR1) mRNA was upregulated in the NAc shell and core, whereas its expression was downregulated in the VTA in the both chronic stress/chow group and chronic stress/fat-bingeing group (Figure 11A-D). CRFR1 expression was also increased in the LH of the chronic stress/fat-bingeing group. CRFR1 
A

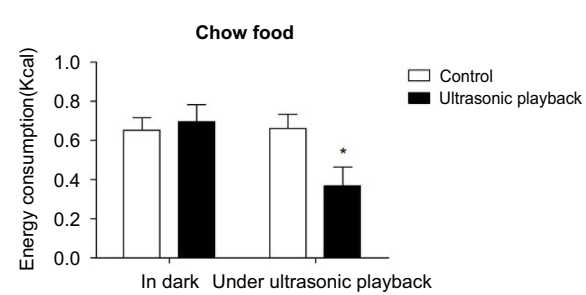

D

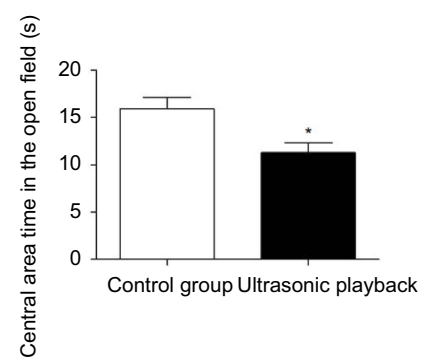

B

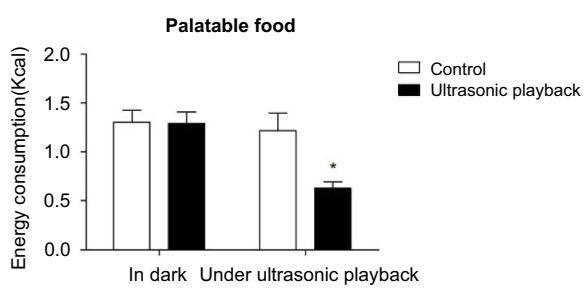

E

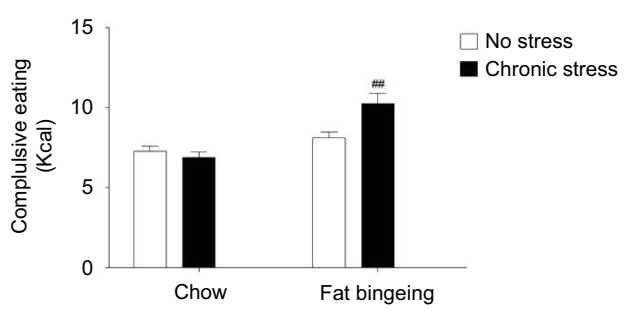

C

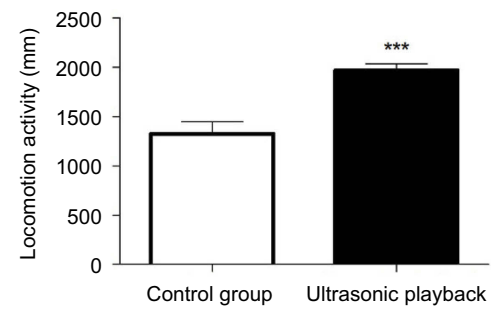

F

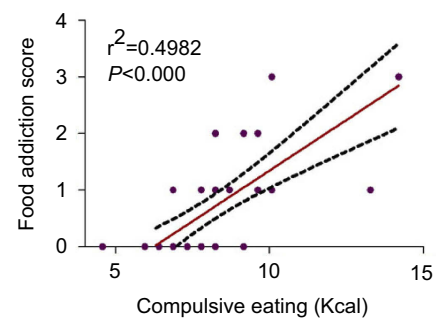

Figure 9 The ultrasonic rat repellent exerts negative effects on both chow food intake (A) and palatable food intake (B).It could increased mices locomotion activities (C) and decreased central area time in the open field test (D). Food intake in the presence of the ultrasonic rat repellent playback was used to measure compulsive eating behavior. Chronic stress aggravated complusive eating in the fat-bingeing mice. (E) Compulsive eating exhibited a strong relationship with the food addiction score (F). * denotes significant differences between control group and due group; \# denotes significant differences between chronic stress/fat-bingeing group and fat-bingeing group $\left(* P<0.05 ;{ }^{\#} P<0.001\right)$.

expression was also downregulated in the NAc shell of the fat-bingeing group.

The expression of DR1 and DR2 in the NAc and MOR in the NAc, LH and VTA of mice in each group was measured to assess addiction-related changes (Figure 12A-H). DR1 expression was not significantly different among the groups. DR2 expression was upregulated in the NAc core of the chronic stress/chow and chronic stress/fat-bingeing groups, while it was downregulated in the NAc shell of the fatbingeing group compared with expression in the mice in the chow group. MOR expression was upregulated in the NAc core of the chronic stress/chow group and chronic stress/fat-bingeing group but was downregulated in the NAc shell. No significant difference in MOR expression was observed in LH and VTA among groups.

We also performed immunofluorescence staining to further assess the changes in the levels of these molecules in the NAc. DR2s were abundantly distributed from the shell to the core of the NAc, while the MOR was mainly expressed in the NAc shell (Figure S1 and S2). In the present study, we determined the number of positive cells in the slices from each group of mice. Chronic stress increased the expression of DR2 in the NAc shell and core in the fat-bingeing mice, but not mice fed chow (Figures 13 and 15). However, MOR expression was increased in the NAc of mice in both the chronic stress/chow and chronic stress/fat-bingeing groups (Figures 14 and 15).

\section{Discussion}

Although multiple studies have reported that chronic stress is a critical risk factor for obesity, ${ }^{25-27}$ the present study verified the results from the perspective of food addiction. Chronic stress promoted the development of food addiction and contributed to the development of obesity. Chronic stress not only aggravated the binge eating behaviors but also compulsive eating behaviors. Moreover, the animals' motivation for palatable food increased after exposure to chronic stress while feeding. These feedingrelated behaviors are the main features of food addiction. Chronic stress obviously increased the FAS and promoted the development of obesity in the mice fed palatable food.

Although palatable food comforts stressed individuals and mice exposed to stress selectively consume palatable food, the explanations are not as simple. ${ }^{8}$ Mice exposed to acute stress decreased rather than increased their intake of palatable food in our study. However, mice exposed to chronic stress increased their intake of palatable food. The process underlying the shift from decreased to increased intake depends upon adaptations in the reward circuitry in the brain. ${ }^{28}$ When animals are exposed to severe stress, dysregulated DA release and CRF in the reward circuitry drives the switch in the appetitive response to palatable food to an aversive response. ${ }^{29}$ When repeatedly exposed to a stressor, mice gradually 

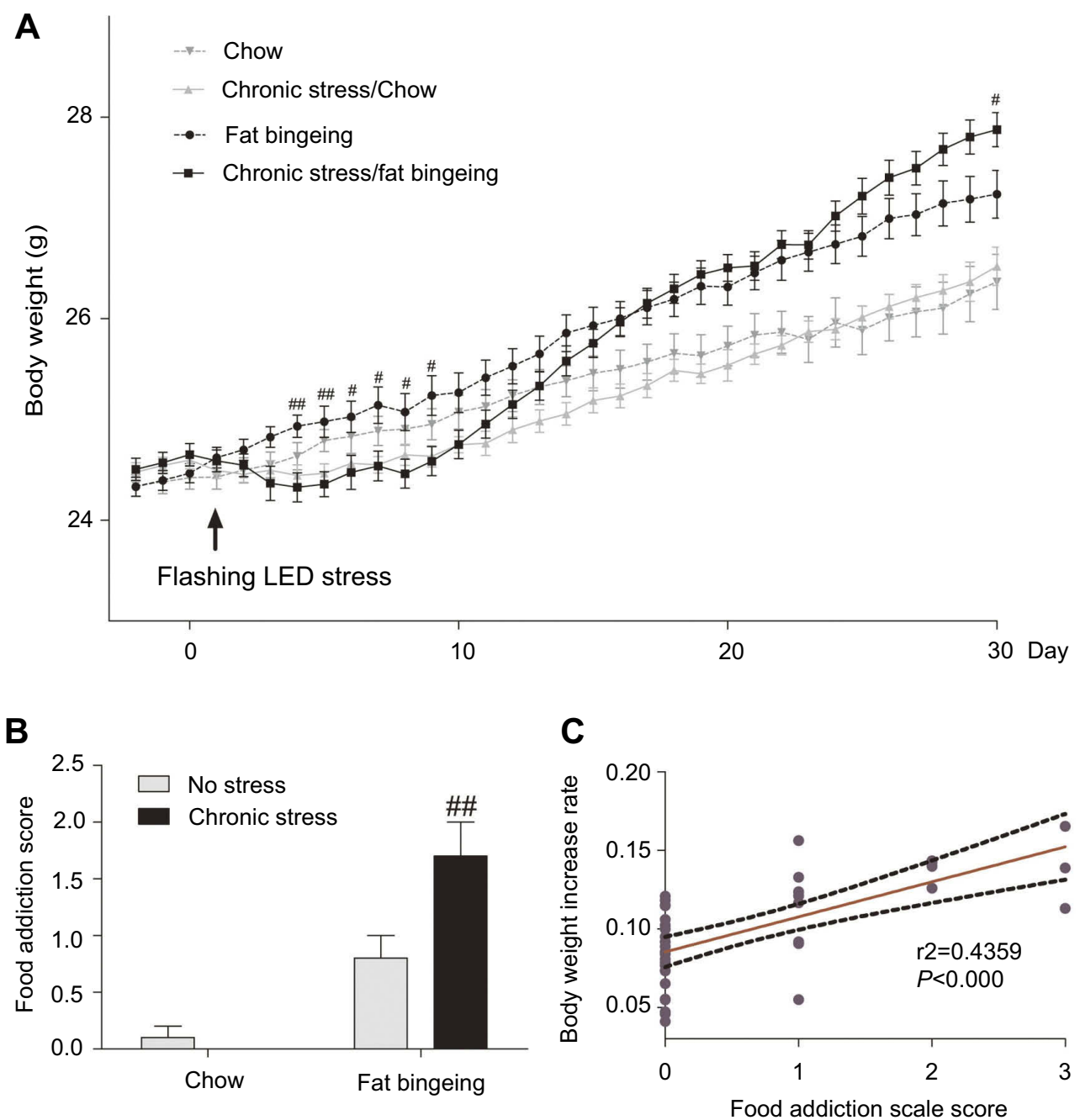

Figure 10 Chronic stress promoted the progress of body weight gain in the fat-bingeing mice $(\mathbf{A})$ and their food addiction score (B). The rate of increase in body weight was positively correlated with the food addiction scale score (C). \# denotes significant differences between chronic stress/fat-bingeing group and fat-bingeing group $\left(\# P<0.05 ;{ }^{\#} P<0.001\right)$

habituated to the stressor and their food consumption was restored. Mice selectively increase their response to palatable food cues following chronic stress. ${ }^{30}$ In addition, chronic stress exposure enhances vulnerability to cueinduced relapse. ${ }^{31}$ Thus, mice selectively enhance their motivation for palatable food after repeated stress exposures. The dysregulation of the reward system increases vulnerability to palatable food dependency. The shift from acute stress to chronic stress reflected the process of dysregulation of reward system in the brain and also the development of food addiction.

The shift from acute stress to chronic stress also studied extensively in clinical studies. ${ }^{2}$ Acute stress induces hyperactivity of HPA-axis but patients in chronic stress exhibited hypoactivity of HPA-axis. Dysregulation of HPA activity is critically responsible for the stress-inducing obesity. ${ }^{3}$ Population with HPAaxis hypoactivity always exhibited a worse metabolic problems and obesity whereas chronic depression patients with HPA-axis hyperactivity do not suffer from metabolic disorders. ${ }^{2}$ Thus, the status of HPAaxis activity might be related with scale of obesity and metabolic. However, studies also indicated the relationship between HPA-axis activities and addiction. ${ }^{32,33} \mathrm{HPA}$ activity in some level reflects the risk of addiction. ${ }^{33}$ Therefore, dysregulation of HPAaxis contributes to the development of food addiction.

Recent studies also indicated that chronic stress drives the dysfunction of the motivational system mediated by the HPA-axis. ${ }^{34}$ The release of CRF from the hypothalamus also plays a critical role in the regulation of reward, motivation, and cravings for foods. ${ }^{29,35} \mathrm{CRF}$ regulates 
A

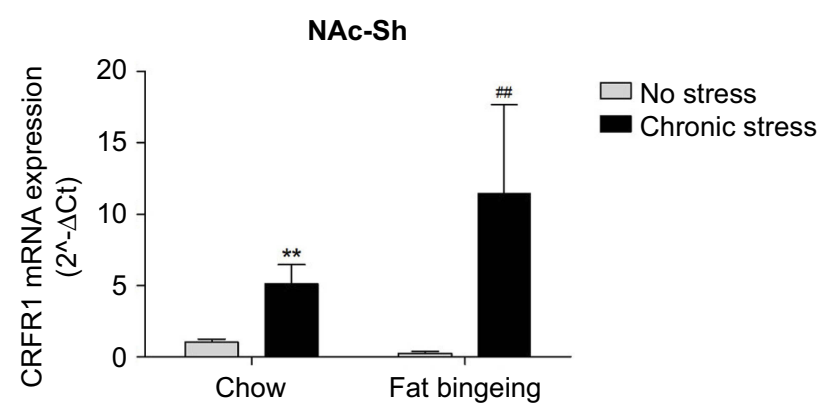

C

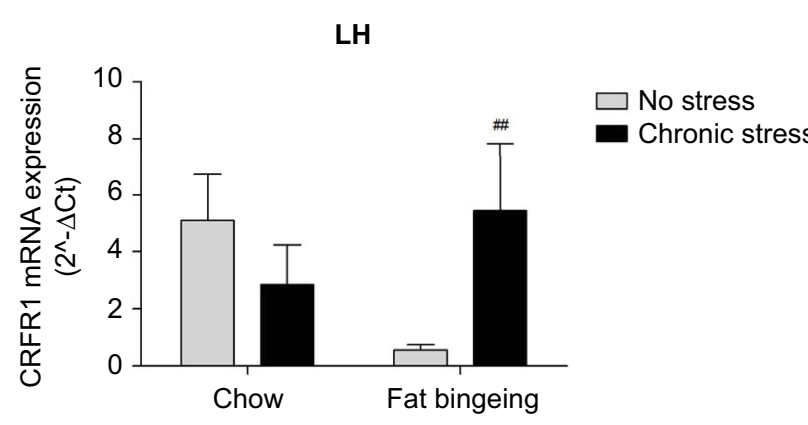

B

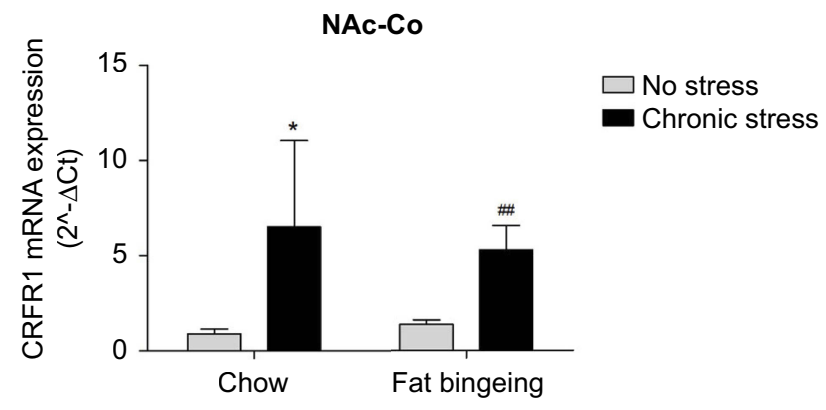

D

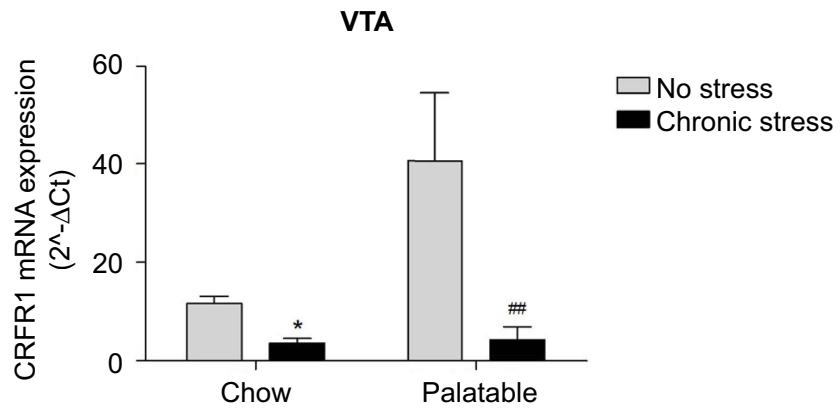

Figure II Expression of the CRFRI mRNA in the nucleus accumbens shell, core, LH and VTA in all groups. (A) Chronic stress increased CRFRI mRNA expression of nucleus accumbens shell both in the chow food feeding and fat bingeing feeding mice. (B) Chronic stress increased CRFRI mRNA expression of nucleus accumbens core both in the chow food feeding and fat bingeing feeding mice. (C) Chronic stress increased CRFRI mRNA expression of LH in the fat bingeing feeding mice. (D) Chronic stress decreased CRFRI mRNA expression of VTA both in the chow food feeding mice and fat bingeing feeding mice. * denotes significant differences in daily food intake between the chronic stress/chow group and chow group, and \# denotes significant differences between the fat-bingeing group and chronic stress/fat-bingeing group $(* P<0.05$, $\left.* * P<0.01,{ }^{\#} P<0.01\right)$.

Abbreviations: NAc-shell, nucleus accumbens shell; NAc-core, nucleus accumbens core; LH, lateral hypothalamus; VTA, ventral tegmental area; CRFRI, corticotropinreleasing factor receptor $\mathrm{I}$.

the release of DA in the NAc, which is involved in processes of reward, motivation and other important pathways relevant to food intake. ${ }^{29}$ However, severe stress abolishes these effects. ${ }^{29}$ CRFR1 is considered the primary receptor mediating stress-related psychopathologies and thus is thought to be responsible for stress-induced eating and cravings. Based on our results, chronic stress downregulated the expression of CRFR1 in the VTA, in which the majority of DA neurons project to the NAc. In contrast, CRFR1 expression was upregulated in the NAc shell and core and LH. Interestingly, different nuclei exhibited different responses to chronic stress. We presume that these nuclei might receive regulatory information from both CRF and glucocorticoids (GCs). GCs might further regulate the expression of CRFR1; GCs might induce a negative feedback regulatory mechanism in the VTA might to modulate CRF expression in the PVN, while the LH and NAc receive positive feedback regulation.
We also detected MOR expression in the NAc, LH and VTA and found that changes in MOR expression might be one of the possible mechanisms involved in the effects of chronic stress. Chronic stress increased MOR expression in both mice fed chow and palatable food. Thus, the changes in MOR expression appear to be relevant to chronic stress. MOR expression increases endogenous opioid release in the NAc and subsequently increases the motivation for the reward. In the stressed environment, palatable food counters the negative mood. ${ }^{8}$ Repeated stimulation drives the motivation for the palatable food. The upregulation of MOR has been shown to excite dopaminergic neurons and contribute to the development of behavioral sensitization. ${ }^{36}$ The possible relationship and molecular mechanisms should be investigated in future studies.

Chronic stress decreased DA release from the VTA following repeated exposure to palatable foods. Thus, we examined the levels of DA receptors in the NAc shell and 

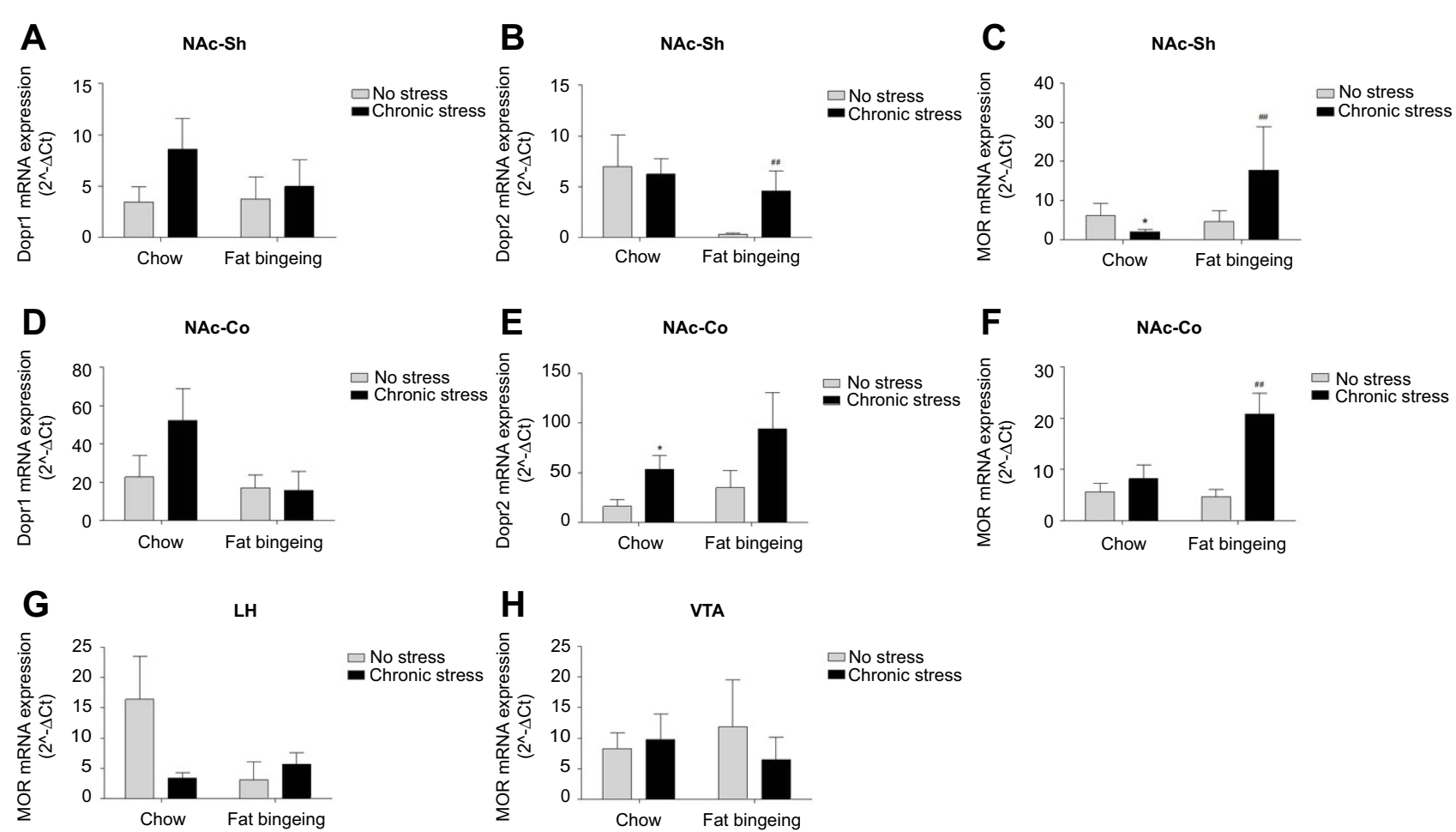

Figure 12 Expression of the DRI, DR2 and MOR mRNAs in the nucleus accumbens shell, nucleus accumbens core and VTA of all groups. (A) Chronic stress takes no significant effect on the DRI expressions of nucleus accumbens shell. (B) Chronic stress increased DR2 expression of nucleus accumbens shell in fat-bingeing feeding mice. (C) Chronic stress increased MOR expression of nucleus accumbens shell both in chow food feeding mice and fat-bingeing feeding mice. (D) Chronic stress takes no significant effect on the DRI expressions in nucleus accumbens core. (E) Chronic stress increased DR2 expression of nucleus accumbens core in chow food feeding mice. (F) Chronic stress increased MOR expression of nucleus accumbens core both in fat-bingeing feeding mice. (G) There are no significant differences in MOR expression of LH between no stress and chronic stress group. (H) There are no significant differences in MOR expression of VTA between no stress and chronic stress group. *denotes significant differences in daily food intake between the chronic stress/chow group and chow group, and \# denotes significant differences between the fat-bingeing group and chronic stress/fat-bingeing group $\left({ }^{*} P<0.05\right.$, ${ }^{\#} P<0.05$, $\left.{ }^{\prime \prime} P<0.01\right)$.

Abbreviations: NAc-shell, nucleus accumbens shell; NAc-core, nucleus accumbens core; LH, lateral hypothalamus; VTA, ventral tegmental area; DRI, dopamine receptor I; DR2, dopamine receptor 2; MOR, mu-opioid receptor.

core. DR2 expressed in the NAc core, but not the shell, participates in the regulatory effects of chronic stress. DR2 are required to regulate the process of food addiction. Downregulation of DR2 occurs in both the obese and food addiction models. ${ }^{37,38}$ A reduction in the DR2 level increases vulnerability to addiction. Knockdown of striatal DR2 promotes the development of food addictionlike behaviors. ${ }^{37}$ The mice in the fat-bingeing group exhibited similar behaviors. However, DR2 expression was upregulated in the stress/fat-bingeing group, which were exposed to chronic stress and provided repeated access to palatable food. Other relevant studies reported similar results. ${ }^{39-43}$ Chronic stress increases DAT binding in the striatum ${ }^{39}$ and NAc, ${ }^{40}$ as well as DR2 levels in the PFC. $^{44}$ In contrast, knockout of DR2 in the NAc core suppresses chronic stress-induced cocaine behavioral sensitization, drug seeking and relapse behaviors. ${ }^{45}$ The results may seem paradoxical. However, our results might account for the apparent discrepancy. Stresscoupled addiction might be a different aspect of these behaviors. Traditional addiction models, similar to the condition of the consumption of palatable food by mice in our study, provide the repeated palatable foods or drugs to induce behavioral sensitization. These repeated reward signals result in decreased DA levels in the NAc, and chronic stimulation results in the downregulation of DR2 and the loss of synaptic plasticity. The underlying mechanisms may involve the continuous decrease in cAMP levels after DA receptor binding to a ligand. However, chronic stress produces the opposite effect. In the present study, chronic stress increased CRFR1 expression. The binding of CRFR1 to CRF increases $\mathrm{Ca}^{2+}$ and cAMP levels. ${ }^{34}$ In addition, chronic stress increases dopaminergic transmission and DR2 expression. Considering the evidence described above, we postulate that stress-coupled food addiction involves different mechanisms. The present study did not detect changes in DR1 levels in the NAc, although a previous study indicated that DR1 is possibly involved in the process of chronic stress. ${ }^{30}$ 

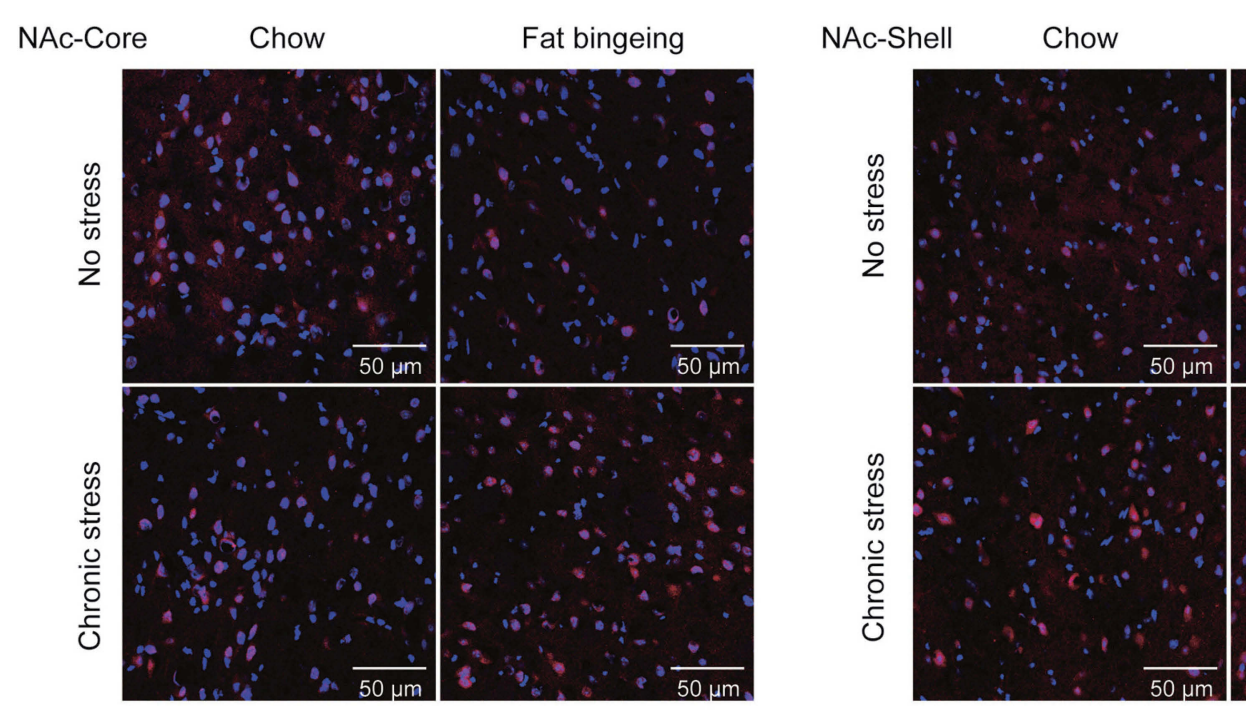

\section{Fat bingeing}

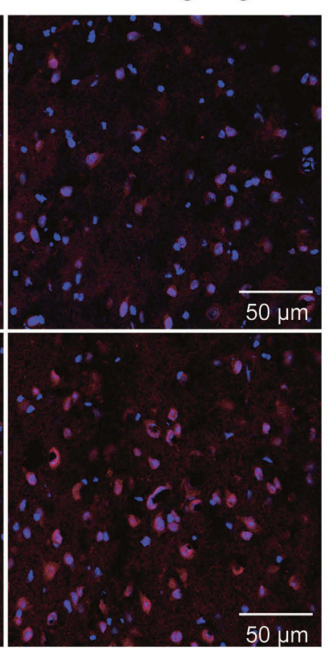

Figure 13 Images of immunofluorescence staining show DR2-positive cells in the slices from each group.
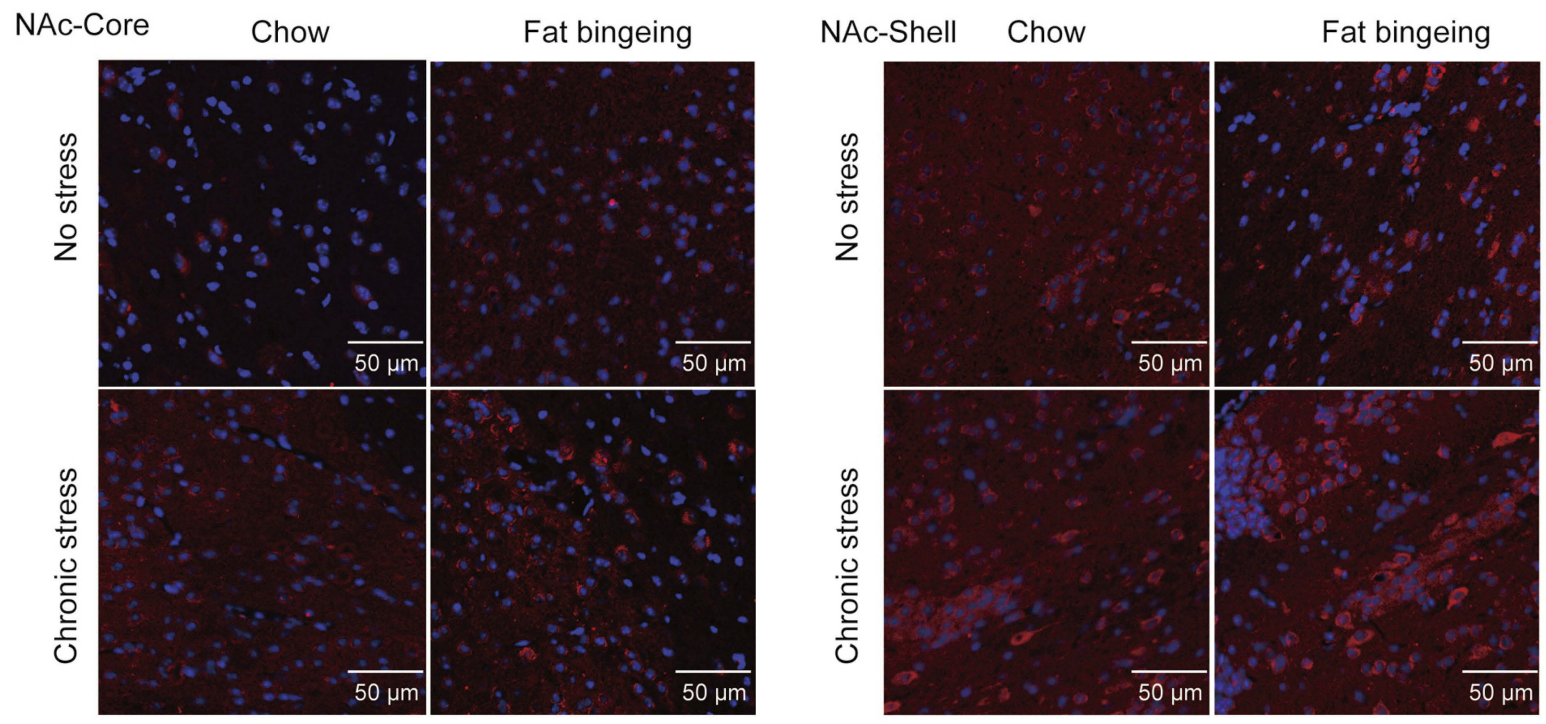

Figure 14 Images of immunofluorescence staining show MOR-positive cells in the slices from each group.

In addition of CRF, changes of peripheral hormone induced by dysregulation of HPA-axis might be also responsible for the changes of reward system. ${ }^{46}$ Stress increases levels of peripheral corticosterone and GC. ${ }^{4}$ This elicits high expressions of NPY, which is a wellknown peripheral orexigenic hormone and increases feeding. ${ }^{4,46,47}$ It could regulate motivation for palatable foods its receptors extensively expressed in hypothalamic and extrahypothalamic regions. ${ }^{48}$ Central DA could regulate expression of peripheral NYP through DAR-PI3K-NF- kappa B signaling pathway in the hypothalamus. ${ }^{49}$ Peripheral NYP also elicits changes of opioid receptors to increase motivation for foods. ${ }^{47,50}$ Chronic stress could reduce NYP expressing GABAergic neurons densities in orbitofrontal cortex ${ }^{51}$ and hippocampus and seral other regions in the brain. ${ }^{52}$ Loss of inhibitory control of GABAergic neurons contributes to development of impulsivity diseases ${ }^{53}$ which also exists in food addiction. ${ }^{20}$ Therefore, NYP might be another potential mechanism involved in food addiction although it was not studied in the present research.

In the present study, we initially applied the ultrasonic rat repellent to produce a negative effect and evaluate compulsive eating behaviors. The method did not affect feeding behavior in itself, which is unusual, as previously 


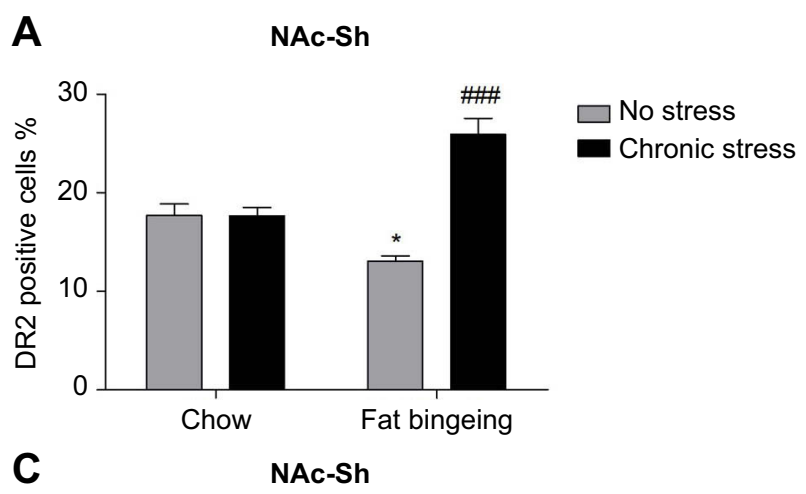

B NAc-Co
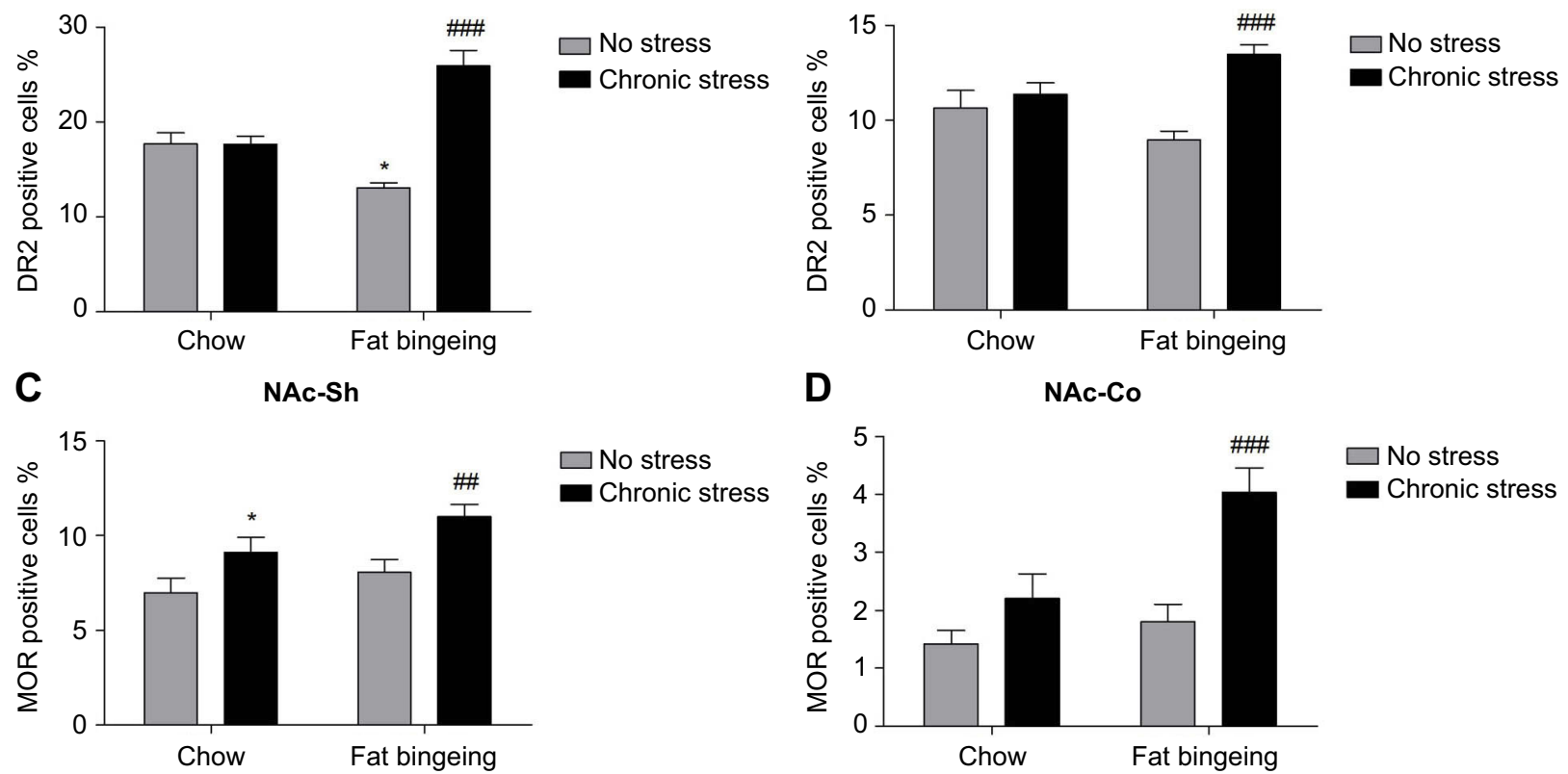

Figure 15 MOR and DR2 expression in the nucleus accumbens (NAcc). (A) Fat bingeing feeding decreased DR2 in NAc-shell but chronic stress increased DR2 of NAcshell in fat-bingeing feeding mice. (B) Chronic stress increased DR2 of NAc-core in fat-bingeing feeding mice. (C) Chronic stress increased MOR of NAc-shell both in chow food feeding mice and fat-bingeing feeding mice. (D) Chronic stress increased MOR of NAc core in fat-bingeing feeding mice. *denotes significant differences in daily food intake between the fat-bingeing group and chow group, and \# denotes significant differences between the fat-bingeing group and chronic stress/fat-bingeing group $(* P<0.05$, $\left.{ }^{\#} P<0.01 ;{ }^{\prime \prime} P<0.001\right)$.

Abbreviations: NAc-shell, nucleus accumbens shell; NAc-core, nucleus accumbens core; DR2, dopamine receptor 2; MOR, mu-opioid receptor.

reported methods such as shock and acupuncture alter feeding behaviors. Previous methods always induce bodily injury and passively inhibited feeding behaviors. ${ }^{54}$ This situation does not simulate the relationship between feeding and chronic stress in humans. Humans employ an active feeding process. When humans are exposed to severe stress, they always actively intake more or less food but are not disturbed passively in response to bodily injury. Instead, the ultrasonic rat repellent did not disturb limb activities but aroused fear and escape behaviors by sending out ultrasound waves with frequencies of 20-50 kHz. Mice in the present study that were exposed to the ultrasound waves exhibited anxiety behaviors, although their locomotion increased. Thus, the ultrasonic rat repellent produced the alarming effect that prompted the mice to escape from the stimulus. The effect was also reported previously. ${ }^{19}$ When mice received a harmful stimulus or were exposed to aversive situations, such as predator exposure and fighting or during drug withdrawal, ${ }^{55}$ they also emit $20-25-\mathrm{kHz}$ ultrasound signals. ${ }^{56}$ When the recording of ultrasound signals is played back to rats, they exhibit freezing behaviors, which is a common response to distal threatening stimuli. $^{56}$ The uncomfortable signal received by the sensory organ likely produces alarming signals and disturbs feeding. Ultrasound signals decreased the intake of both chow and palatable food. Based on these findings, we applied this method to evaluate compulsive eating behaviors. The intake of palatable food by mice exposed to the ultrasound wave predicted the FAS. When mice consumed a greater amount of palatable food in the compulsive eating test, they presented a higher FAS. In addition, the ultrasonic vocalizations of mice are regulated by the reward system. ${ }^{55,57,58}$ Dysregulation of the reward system in subjects with addiction-related diseases might blunt ultrasound signals. This method appears to be suitable to detect the sensitivity of the reward system to respond to harmful or helpful stimulus. Therefore, the assessment of food consumption during exposure to an ultrasound wave might be a useful and easily manipulatable method to evaluate compulsive eating behaviors. However, the present study did not assess the underlying mechanisms. Future studies should be designed to study this new method.

\section{Acknowledgments}

This work was supported by grants (2018YFA0107900, 31771491, 81641056, 2019CXJQ01) from Ministry of Science and Technology of China, the National Nature Science Foundation and Shanghai Manipal Government; supported by Fundamental Research Funds for the Central Universities (lzujbky-2017-80). 


\section{Disclosure}

The authors report no conflicts of interest in this work.

\section{References}

1. Boscarino JA, Erlich PM, Hoffman SN, Zhang X. Higher FKBP5, COMT, CHRNA5, and CRHR1 allele burdens are associated with PTSD and interact with trauma exposure: implications for neuropsychiatric research and treatment. Neuropsychiatr Dis Treat. 2012;8:131-9. doi:10.2147/NDT.S29508

2. Maripuu M, Wikgren M, Karling P, Adolfsson R, Norrback KF. Relative hypocortisolism is associated with obesity and the metabolic syndrome in recurrent affective disorders. $J$ Affect Disord. 2016;204:187-196. doi:10.1016/j.jad.2016.06.024

3. Incollingo Rodriguez AC, Epel ES, White ML, Standen EC, Seckl JR, Tomiyama AJ. Hypothalamic-pituitary-adrenal axis dysregulation and cortisol activity in obesity: A systematic review. Psychoneuroendocrinol. 2015;62:301-318. doi:10.1016/j. psyneuen.2015.08.014

4. Zhang L, Lee IC, Enriquez RF, et al. Stress- and diet-induced fat gain is controlled by NPY in catecholaminergic neurons. Mol Metab. 2014;3(5):581-591. doi:10.1016/j.molmet.2014.05.001

5. Aschbacher K, Kornfeld S, Picard M, et al. Chronic stress increases vulnerability to diet-related abdominal fat, oxidative stress, and metabolic risk. Psychoneuroendocrinology. 2014;46:14-22. doi:10.1016/j. psyneuen.2014.04.003

6. Chao AM, Jastreboff AM, White MA, Grilo CM, Sinha R. Stress, cortisol, and other appetite-related hormones: prospective prediction of 6-month changes in food cravings and weight. Obesity. 2017;25 (4):713-720. doi:10.1002/oby.21790

7. Berg Schmidt J, Johanneson Bertolt C, Sjodin A, et al. Does stress affect food preferences? A randomized controlled trial investigating the effect of examination stress on measures of food preferences and obesogenic behavior. Stress. 2018;21(6):556-563. doi:10.1080/10253890

8. Tomiyama AJ, Dallman MF, Epel ES. Comfort food is comforting to those most stressed: evidence of the chronic stress response network in high stress women. Psychoneuroendocrinology. 2011;36 (10):1513-1519. doi:10.1016/j.psyneuen.2011.04.005

9. Dallman MF, Pecoraro N, Akana SF, et al. Chronic stress and obesity: a new view of "comfort food". Proc Natl Acad Sci U S A. 2003;100 (20):11696-11701. doi:10.1073/pnas.1934666100

10. Renna ME, O'Toole MS, Spaeth PE, Lekander M, Mennin DS. The Association between anxiety, traumatic stress, and obsessive-compulsive disorders and chronic inflammation: a systematic review and meta-analysis.Depress Anxiety. 2018;35(11):1081-1094. doi:10.1002/da.22790

11. Taylor SB, Anglin JM, Paode PR, Riggert AG, Olive MF, Conrad CD. Chronic stress may facilitate the recruitment of habitand addiction-related neurocircuitries through neuronal restructuring of the striatum. Neuroscience. 2014;280:231-242. doi:10.1016/j. neuroscience.2014.09.029

12. Kubzansky LD, Bordelois P, Jun HJ, et al. The weight of traumatic stress: a prospective study of posttraumatic stress disorder symptoms and weight status in women. JAMA Psychiatry. 2014;71(1):44-51. doi:10.1001/jamapsychiatry.2013.2798

13. Mason SM, Flint AJ, Roberts AL, Agnew-Blais J, Koenen KC, RichEdwards JW. Posttraumatic stress disorder symptoms and food addiction in women by timing and type of trauma exposure. JAMA Psychiatry. 2014;71(11):1271-1278. doi:10.1001/jamapsychiatry.2014.1208

14. Meule A, Hermann T, Kubler A. Food addiction in overweight and obese adolescents seeking weight-loss treatment. Eur Eat Disord Rev. 2015;23(3):193-198. doi:10.1002/erv.2355

15. Pursey KM, Stanwell P, Gearhardt AN, Collins CE, Burrows TL. The prevalence of food addiction as assessed by the Yale food addiction scale: a systematic review. Nutrients. 2014;6(10):4552-4590. doi: $10.3390 /$ nu6104552
16. Lee NM, Hall WD, Lucke J, Forlini C, Carter A. Food addiction and its impact on weight-based stigma and the treatment of obese individuals in the U.S. and Australia. Nutrients. 2014;6(11):5312-5326. doi:10.3390/nu6115312

17. Pedram P, Wadden D, Amini P, et al. Food addiction: its prevalence and significant association with obesity in the general population. PLoS One. 2013;8(9):e74832. doi:10.1371/journal. pone. 0074832

18. Guerrero Perez F, Sanchez-Gonzalez J, Sanchez I, et al. Food addiction and preoperative weight loss achievement in patients seeking bariatric surgery. Eur Eat Disord Rev. 2018;26(6):645-656. doi:10.1002/erv.2649

19. Litvin Y, Blanchard DC, Blanchard RJ. Rat $22 \mathrm{kHz}$ ultrasonic vocalizations as alarm cries. Behav Brain Res. 2007;182(2):166-172. doi:10.1016/j.bbr.2006.11.038

20. Velazquez-Sanchez C, Ferragud A, Moore CF, Everitt BJ, Sabino V, Cottone P. High trait impulsivity predicts food addiction-like behavior in the rat. Neuropsychopharmacology. 2014;39(10):2463-2472. doi:10.1038/npp.2014.98

21. Avena NM, Bocarsly ME, Hoebel BG. Animal models of sugar and fat bingeing: relationship to food addiction and increased body weight. Methods Mol Biol. 2012;829:351-365. doi:10.1007/9781-61779-458-2_23

22. Heshmati M, Golden SA, Pfau ML, et al. Mefloquine in the nucleus accumbens promotes social avoidance and anxiety-like behavior in mice. Neuropharmacology. 2016;101:351-357. doi:10.1016/j. neuropharm.2015.10.013

23. Segni M, Patrono E, Patella L, Puglisi-Allegra S, Ventura R. Animal models of compulsive eating behavior. Nutrients. 2014;6 (10):4591-4609. doi:10.3390/nu6104591

24. Deroche-Gamonet VBD, Piazza PV. Evidence for addiction-like behavior in the rat. Science. 2004;305(5686):1014-1017. doi:10.1126/science. 1099020

25. Chao AGC, White MA, Sinha R. Food cravings mediate the relationship between chronic stress and body mass index. J Health Psychol. 2015;20(6):721-729. doi:10.1177/1359105315573448

26. Bose MOB, Laferrère B. Stress and obesity: the role of the hypothalamic-pituitary-adrenal axis in metabolic disease. Curr Opin Endocrinol Diabetes Obes. 2009;16(5):340-346. doi:10.1097/ MED.0b013e32832fa137

27. Lincoln L. Social stress, obesity, and depression among women: clarifying the role of physical activity. Ethn Health. 2017;1:1-17. doi:10.1080/13557858.2017.1346190

28. Sharma S, Fernandes MF, Fulton S. Adaptations in brain reward circuitry underlie palatable food cravings and anxiety induced by high-fat diet withdrawal. Int J Obes (Lond). 2013;37(9):1183-1191. doi:10.1038/ijo.2012.197

29. Lemos JC, Wanat MJ, Smith JS, et al. Severe stress switches CRF action in the nucleus accumbens from appetitive to aversive. Nature. 2012;490(7420):402-406. doi:10.1038/nature11436

30. Ball KT, Best O, Luo J, Miller LR. Chronic restraint stress causes a delayed increase in responding for palatable food cues during forced abstinence via a dopamine D1-like receptor-mediated mechanism. Behav Brain Res. 2017;319:1-8. doi:10.1016/j. bbr.2016.11.020

31. Glynn RM, Rosenkranz JA, Wolf ME, et al. Repeated restraint stress exposure during early withdrawal accelerates incubation of cue-induced cocaine craving. Addict Biol. 2018;23(1):80-89. doi: $10.1111 /$ adb. 12475

32. Hildebrandt T, Greif R. Stress and addiction. Psychoneuroendocrinology. 2013;38(9):1923-1927. doi:10.1016/j. psyneuen.2013.06.017

33. Daughters SB, Richards JM, Gorka SM, Sinha R. HPA axis response to psychological stress and treatment retention in residential substance abuse treatment: a prospective study. Drug Alcohol Depend. 2009;105(3):202-208. doi:10.1016/j. drugalcdep.2009.06.026 
34. Henckens MJ, Deussing JM, Chen A. Region-specific roles of the corticotropin-releasing factor-urocortin system in stress. Nature Rev Neurosci. 2016;17(10):636-651. doi:10.1038/nrn.2016.94

35. Kalon E, Hong JY, Tobin C, Schulte T. Psychological and neurobiological correlates of food addiction. Int Rev Neurobiol. 2016;129:85-110. doi:10.1016/bs.irn.2016.06.003

36. Valenta JP, Job MO, Mangieri RA, Schier CJ, Howard EC, Gonzales RA. mu-opioid receptors in the stimulation of mesolimbic dopamine activity by ethanol and morphine in long-evans rats: a delayed effect of ethanol. Psychopharmacology. 2013;228 (3):389-400. doi:10.1007/s00213-013-3041-9

37. Johnson PM, Kenny PJ. Dopamine D2 receptors in addiction-like reward dysfunction and compulsive eating in obese rats. Nat Neurosci. 2010;13(5):635-641. doi:10.1038/nn.2519

38. Wang G-J, Volkow ND, Logan J, et al. Brain dopamine and obesity. Lancet. 2001;357(9253):354-357. doi:10.1016/S0140-6736(00) 03643-6

39. Converse AK, Moore CF, Moirano JM, et al. Prenatal stress induces increased striatal dopamine transporter binding in adult nonhuman primates. Biol Psychiatry. 2013;74(7):502-510. doi:10.1016/j. biopsych.2013.04.023

40. Novak G, Fan T, O`Dowd BF, George SR. Postnatal maternal deprivation and pubertal stress have additive effects on dopamine D2 receptor and CaMKII beta expression in the striatum. Int $J$ Dev Neurosci. 2013;31(3):189-195. doi:10.1016/j. ijdevneu.2013.01.001

41. Lakehayli S, Said N, Khachibi ME, et al. Long-term effects of prenatal stress and diazepam on D2 receptor expression in the nucleus accumbens of adult rats. Neurosci Lett. 2015;594:133-136. doi:10.1016/j.neulet.2015.03.065

42. Said N, Lakehayli S, El Khachibi M, et al. Prenatal stress induces vulnerability to nicotine addiction and alters D2 receptors expression in the nucleus accumbens in adult rats. Neuroscience. 2015;304:279-285. doi:10.1016/j.neuroscience. 2015.07.029

43. Lee AG, Nechvatal JM, Shen B, et al. Striatal dopamine D2/3 receptor regulation by stress inoculation in squirrel monkeys. Neurobiol Stress. 2016;3:68-73. doi:10.1016/j.ynstr.2016.02.001

44. Bagalkot TR, Jin HM, Prabhu VV, et al. Chronic social defeat stress increases dopamine D2 receptor dimerization in the prefrontal cortex of adult mice. Neuroscience. 2015;311:444-452. doi:10.1016/j. neuroscience.2015.10.024

45. Sim HR, Choi TY, Lee HJ, et al. Role of dopamine D2 receptors in plasticity of stress-induced addictive behaviours. Nat Commun. 2013;4:1579. doi:10.1038/ncomms 2598
46. Adam TC, Epel ES. Stress, eating and the reward system. Physiol Behav. 2007;91(4):449-458. doi:10.1016/j.physbeh.2007.04.011

47. Israel Y, Kandov Y, Khaimova E, et al. NPY-induced feeding: pharmacological characterization using selective opioid antagonists and antisense probes in rats. Peptides. 2005;26(7):1167-1175. doi:10.1016/j.peptides.2005.01.017

48. Pandit R, Luijendijk MC, Vanderschuren LJ, la Fleur SE, Adan RA. Limbic substrates of the effects of neuropeptide $\mathrm{Y}$ on intake of and motivation for palatable food. Obesity. 2014;22(5):1216-1219. doi:10.1002/oby.20718

49. Hsieh YS, Chen PN, Yu CH, Kuo DY. Central dopamine action modulates neuropeptide-controlled appetite via the hypothalamic PI3K/NF-kappaB-dependent mechanism. Genes Brain Behav. 2014;13(8):784-793. doi:10.1111/gbb.12174

50. Elghaba R, Bracci E. Dichotomous effects of mu opioid receptor activation on striatal low-threshold spike interneurons. Front Cell Neurosci. 2017;11:385. doi:10.3389/fncel.2017.00385

51. Varga Z, Csabai D, Miseta A, Wiborg O, Czeh B. Chronic stress affects the number of GABAergic neurons in the orbitofrontal cortex of rats Behav Brain Res. 2017;316:104-114. doi:10.1016/j.bbr.2016.08.030

52. Czeh B, Varga ZK, Henningsen K, Kovacs GL, Miseta A, Wiborg O. Chronic stress reduces the number of GABAergic interneurons in the adult rat hippocampus, dorsal-ventral and region-specific differences. Hippocampus. 2015;25(3):393-405. doi:10.1002/hipo.22382

53. Basar KST, Groenewegen H, Steinbusch HW, Visser-Vandewalle V, Temel Y. Nucleus accumbens and impulsivity. Prog Neurobiol. 2010;92(4):533-557. doi:10.1016/j.pneurobio.2010.08.007

54. Moore CF, Panciera JI, Sabino V, Cottone P. Neuropharmacology of compulsive eating. Philos Trans $R$ Soc Lond B Biol Sc. 2018;373:1742.

55. Wohr M, Schwarting RK. Affective communication in rodents: ultrasonic vocalizations as a tool for research on emotion and motivation. Cell Tissue Res. 2013;354(1):81-97. doi:10.1007/s00441-013-1607-9

56. Nobre MJ, Brandão ML. Analysis of freezing behavior and ultrasonic vocalization in response to foot-shocks, ultrasound signals and GABAergic inhibition in the inferior colliculus: effects of muscimol and midazolam. Eur Neuropsychopharmacol. 2004;14(1):45-52.

57. Sadananda M, Wohr M, Schwarting RK. Playback of $22-\mathrm{kHz}$ and $50-\mathrm{kHz}$ ultrasonic vocalizations induces differential c-fos expression in rat brain. Neurosci Lett. 2008;435(1):17-23. doi:10.1016/j. neulet.2008.02.002

58. Brudzynski SM. Ultrasonic calls of rats as indicator variables of negative or positive states: acetylcholine-dopamine interaction and acoustic coding. Behav Brain Res. 2007;182(2):261-273. doi:10.1016/j.bbr.2007.03.004 


\section{Supplementary material}

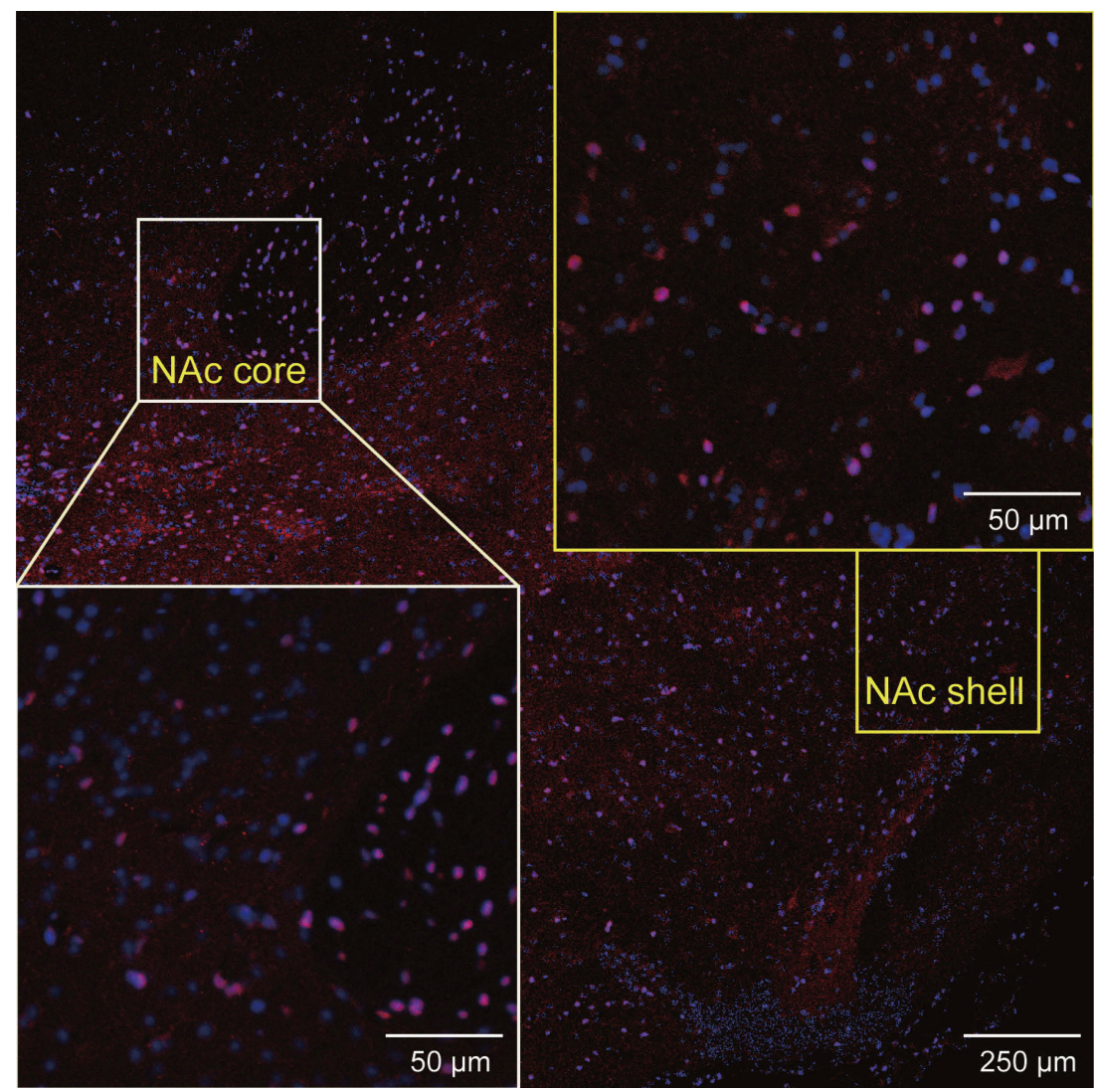

Figure SI Images showing DR2 immunofluorescence in various ROIs in brain sections. 


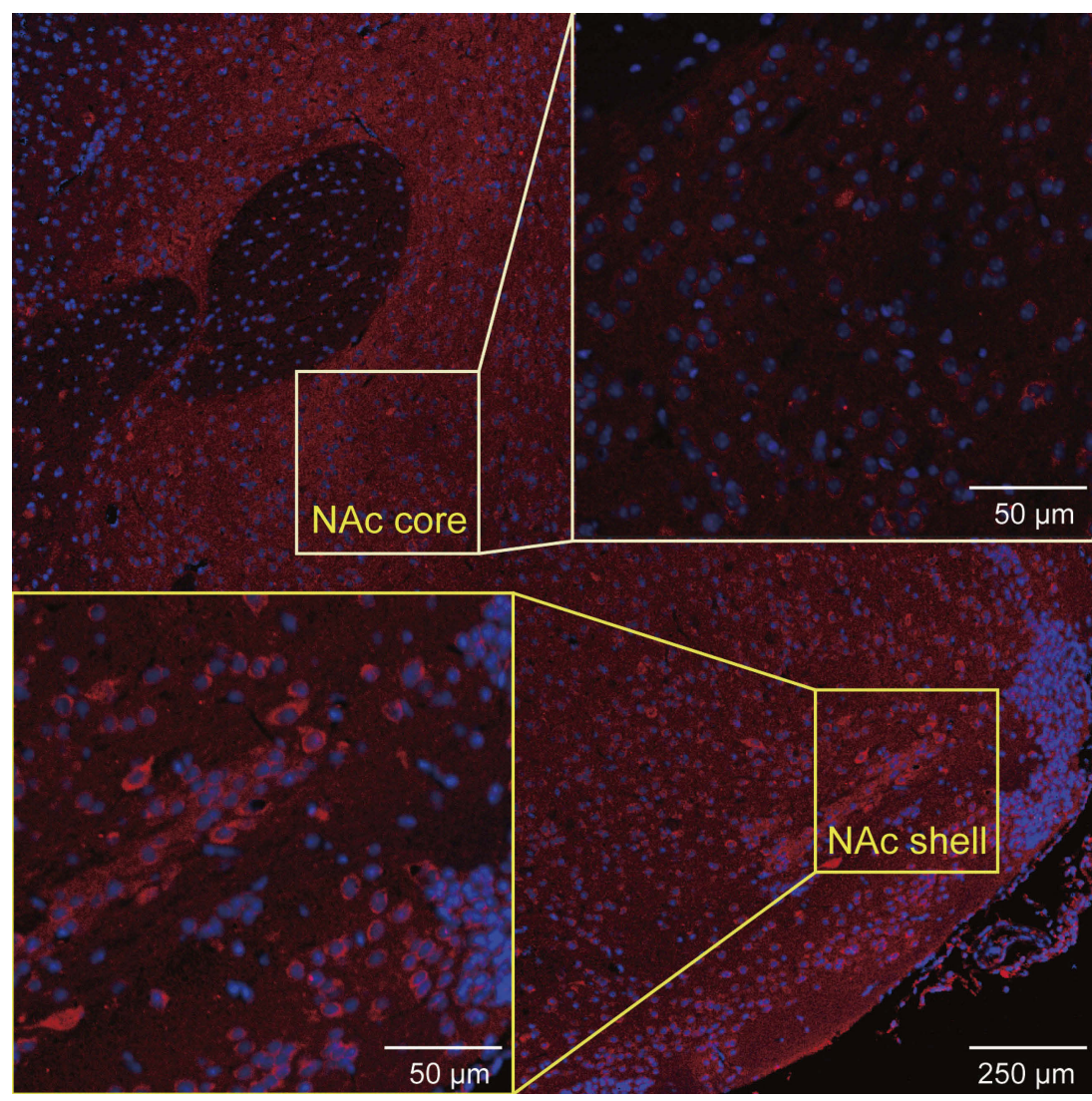

Figure S2 Images showing MOR immunofluorescence in various ROls of the brain slices.

\section{Publish your work in this journal}

Neuropsychiatric Disease and Treatment is an international, peerreviewed journal of clinical therapeutics and pharmacology focusing on concise rapid reporting of clinical or pre-clinical studies on a range of neuropsychiatric and neurological disorders. This journal is indexed on PubMed Central, the 'PsycINFO' database and CAS, and is the official journal of The International Neuropsychiatric Association (INA). The manuscript management system is completely online and includes a very quick and fair peer-review system, which is all easy to use. Visit http://www.dovepress.com/testimonials.php to read real quotes from published authors. 